\title{
Battery Storage for Resilience
}

\section{Background}

As the capital costs of battery storage systems are decreasing, new opportunities to cost-effectively deploy the technology, often paired with renewable energy technologies, are emerging. At the same time, the duration and frequency of natural disasters is increasing. As a result, a growing number of institutions are deploying battery storage systems as a resilient energy solution because traditional backup power solutions, like diesel generators, are not always sufficient, especially during longer-duration and larger-scale disasters.

- On-site diesel fuel supply typically only lasts for a few days because sites may be limited in the amount of fuel they store on-site (due to financial, regulatory, or other constraints).

- It can be difficult to resupply backup diesel generators in the event of extended outages because natural disasters may damage fuel supply chains, or fuel may be diverted to higher priority needs.

- Backup diesel generators are infrequently used and are likely to fail if not properly maintained (a recent study found poorly maintained diesel generators have just a 50\% probability of lasting 48 hours) (Marqusee and Jenket 2020).

- Backup generators typically do not provide monetizable value streams while grid-connected.

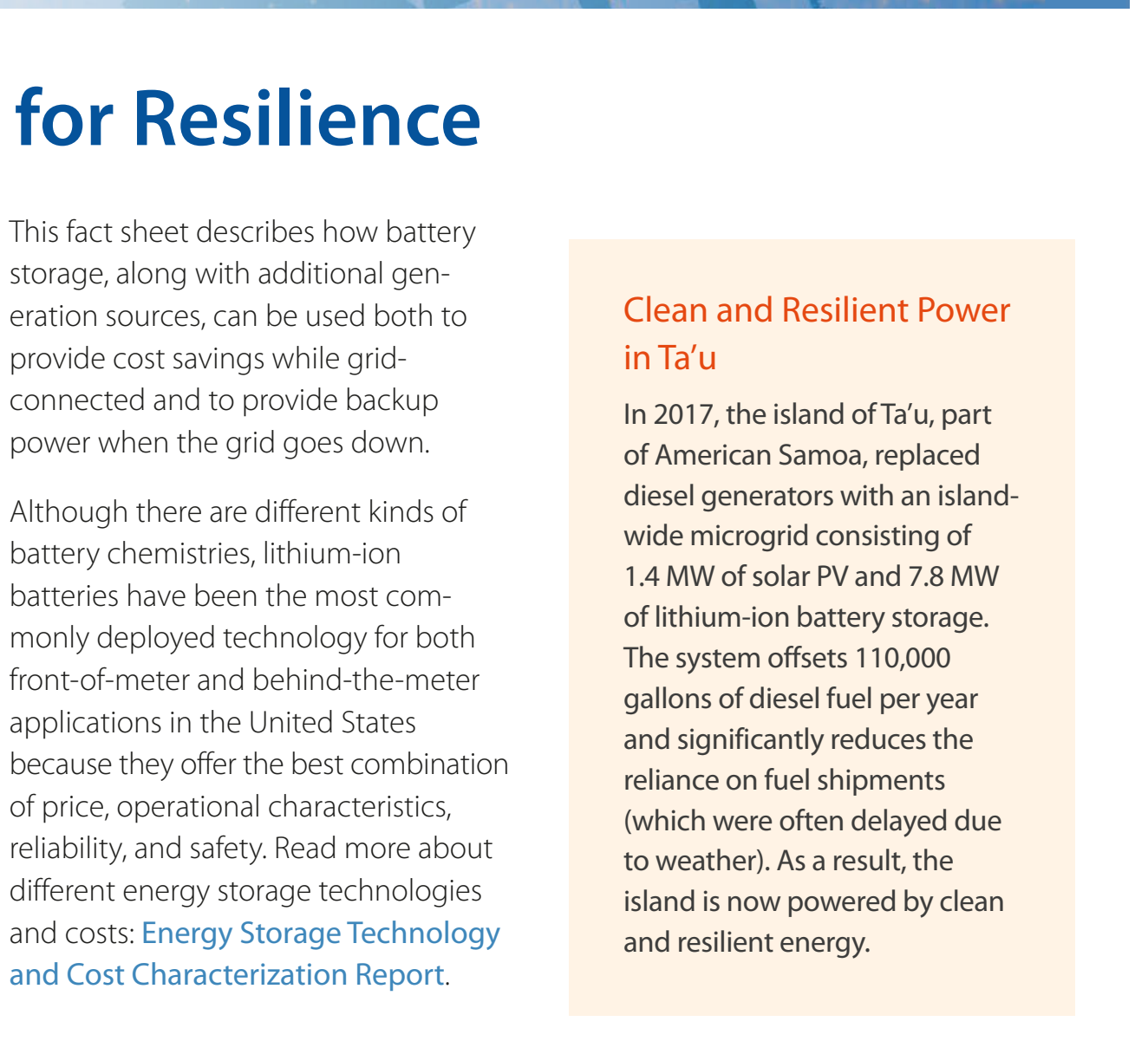

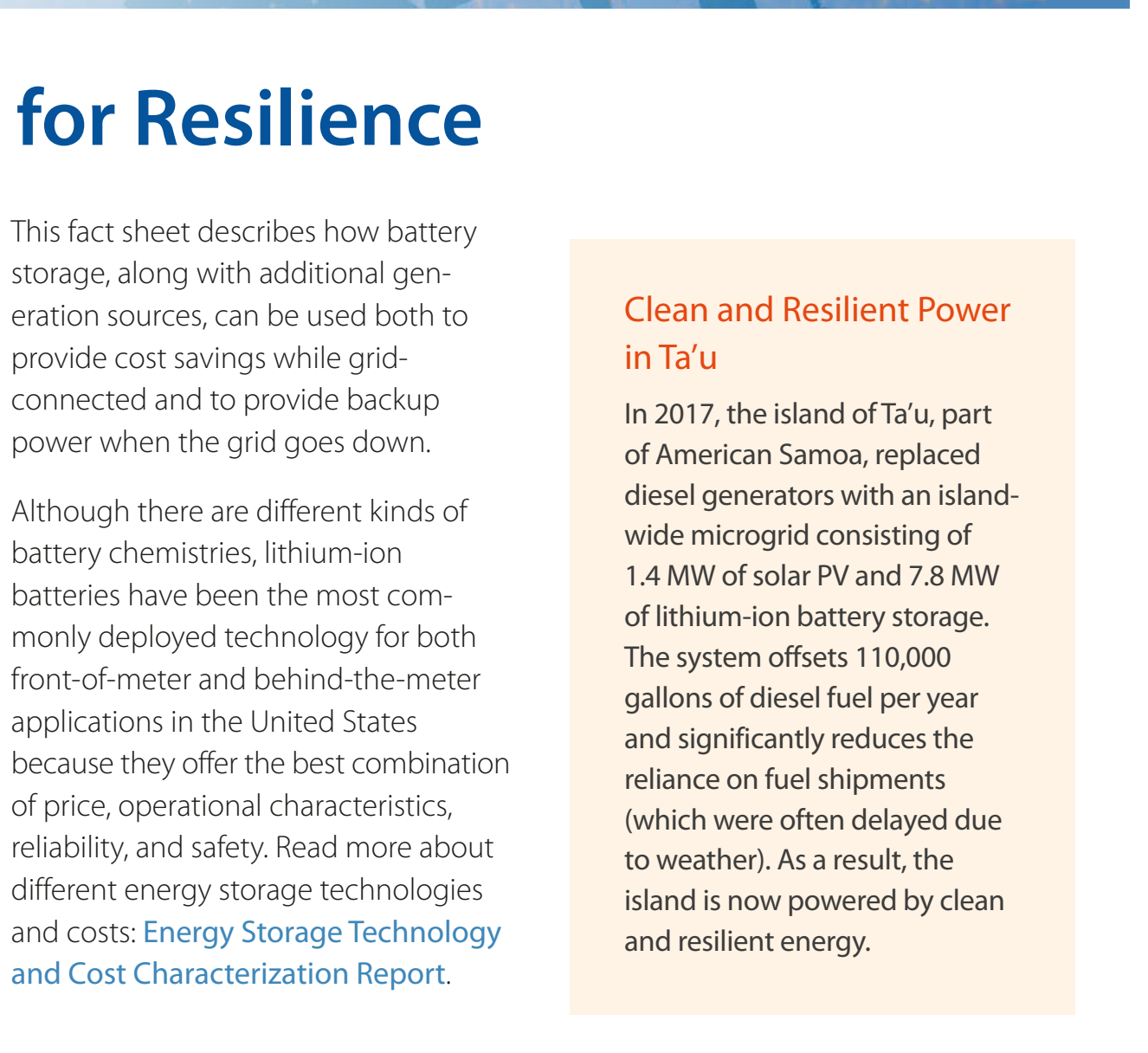

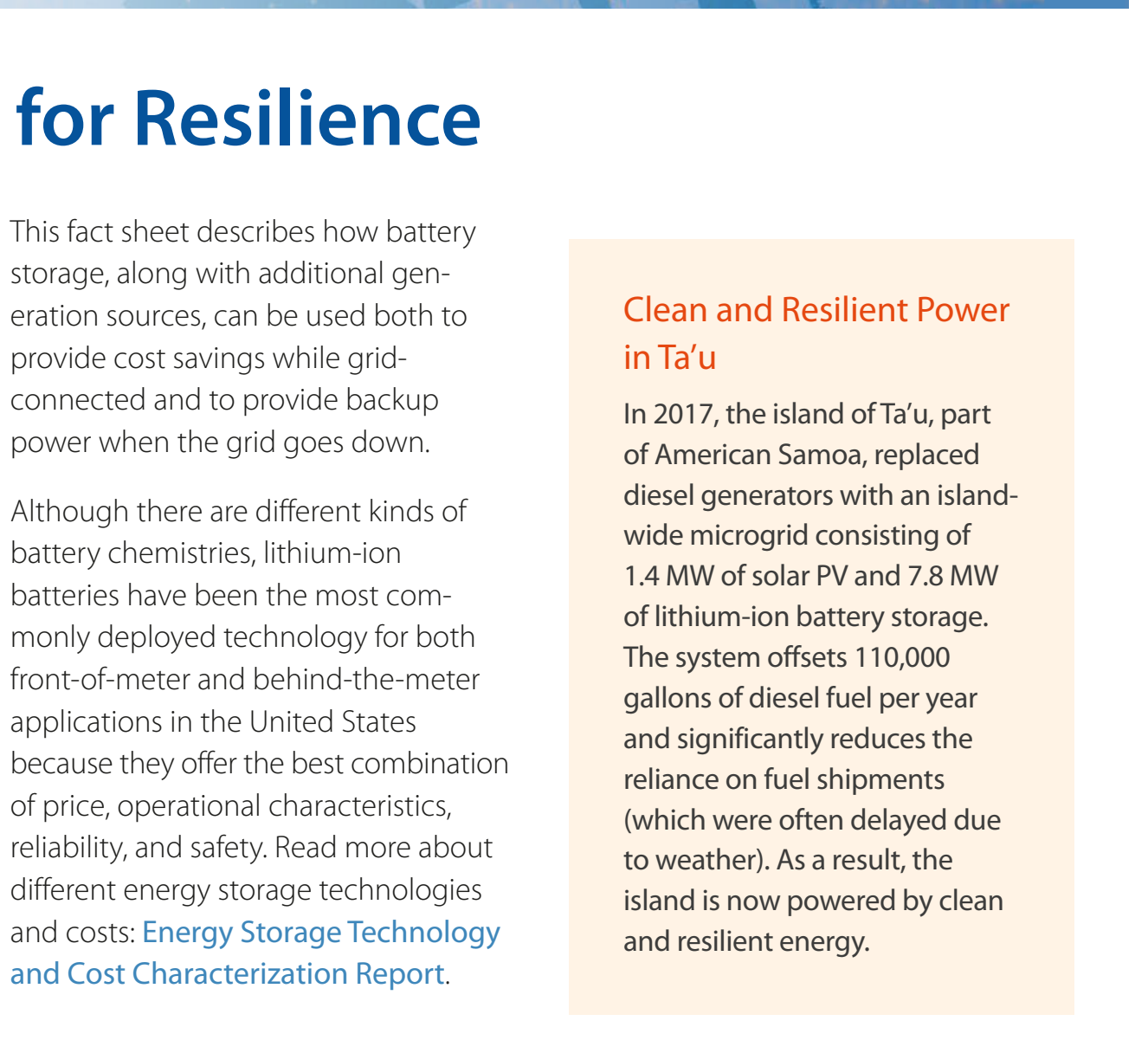

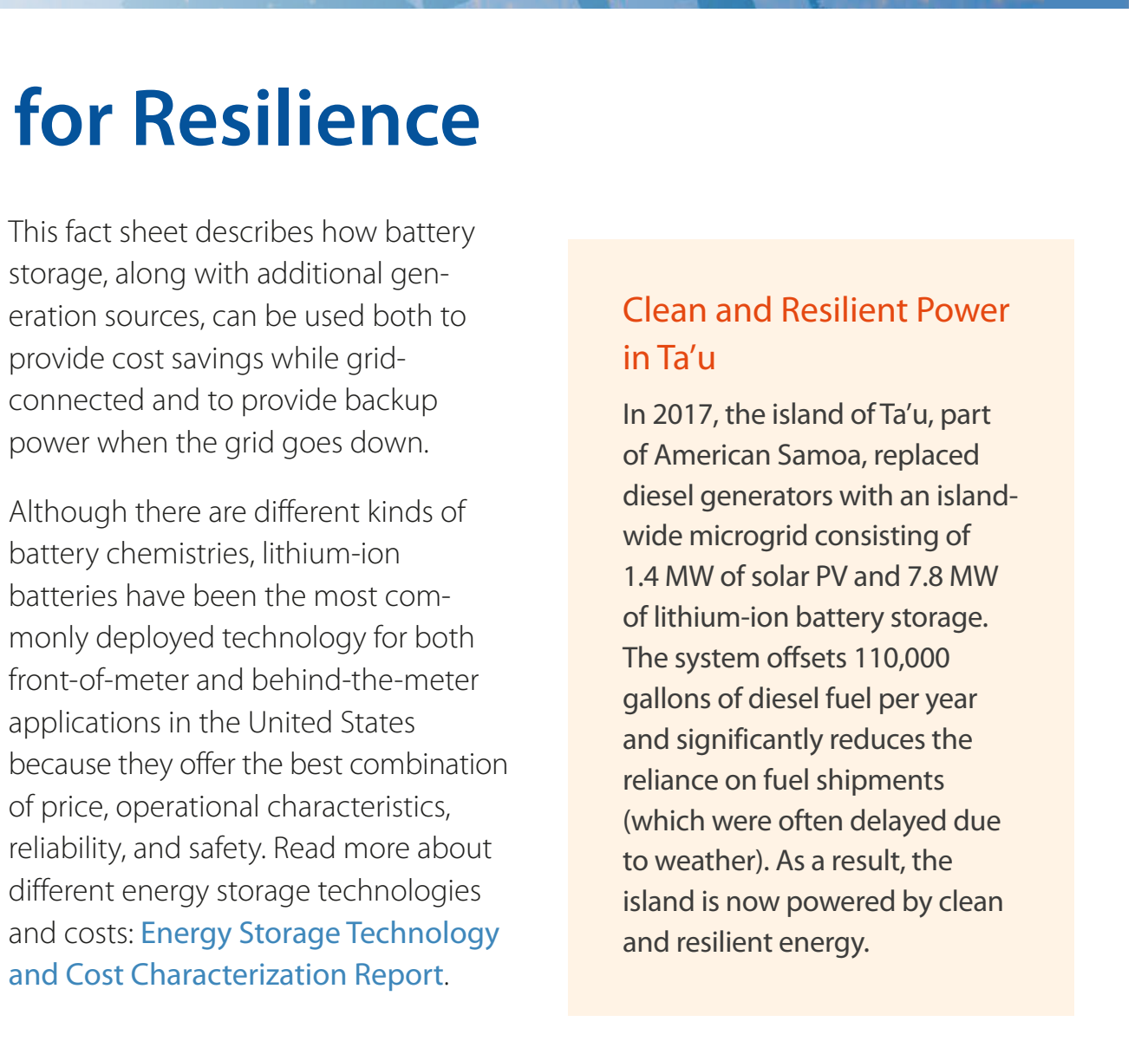

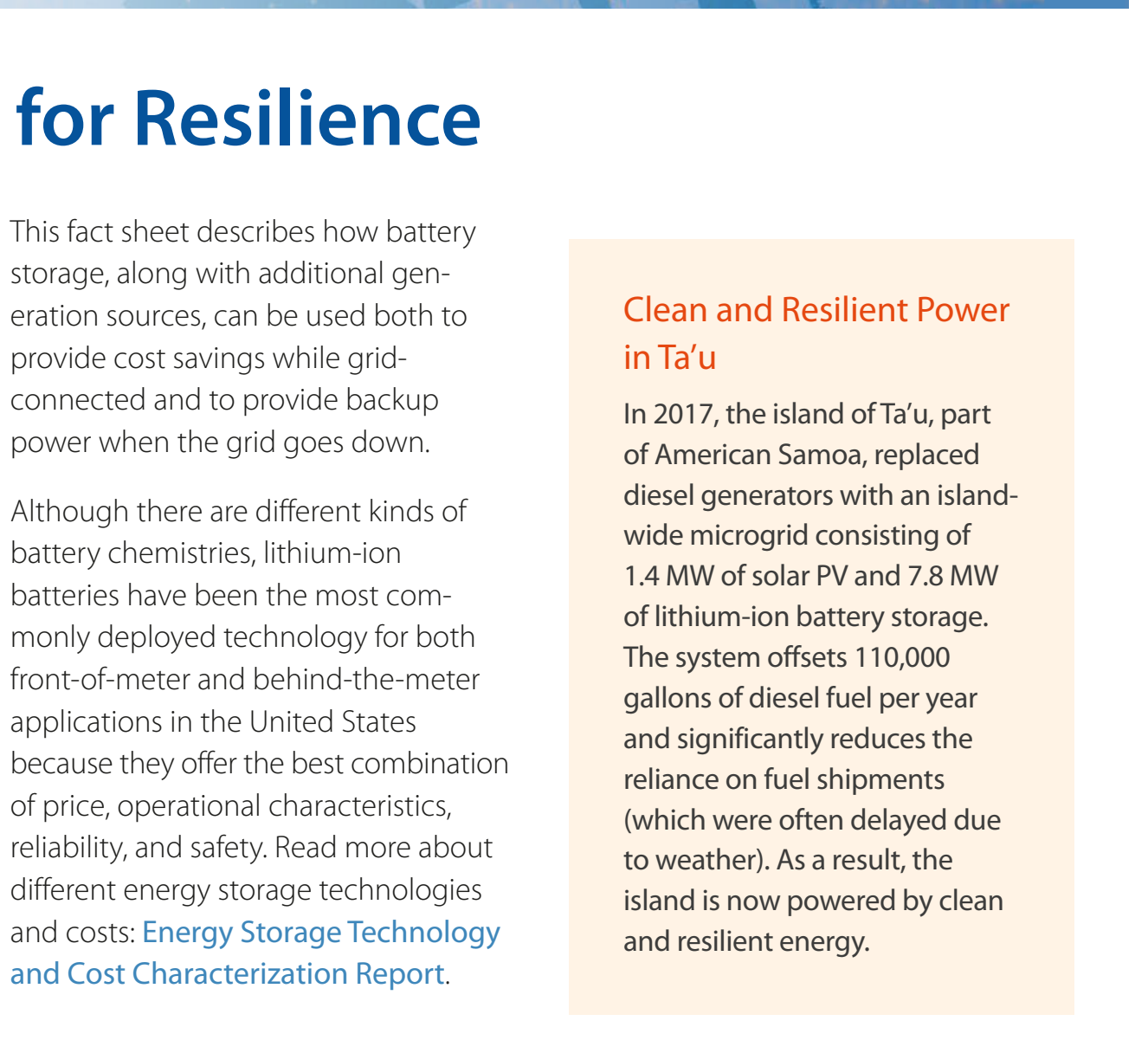

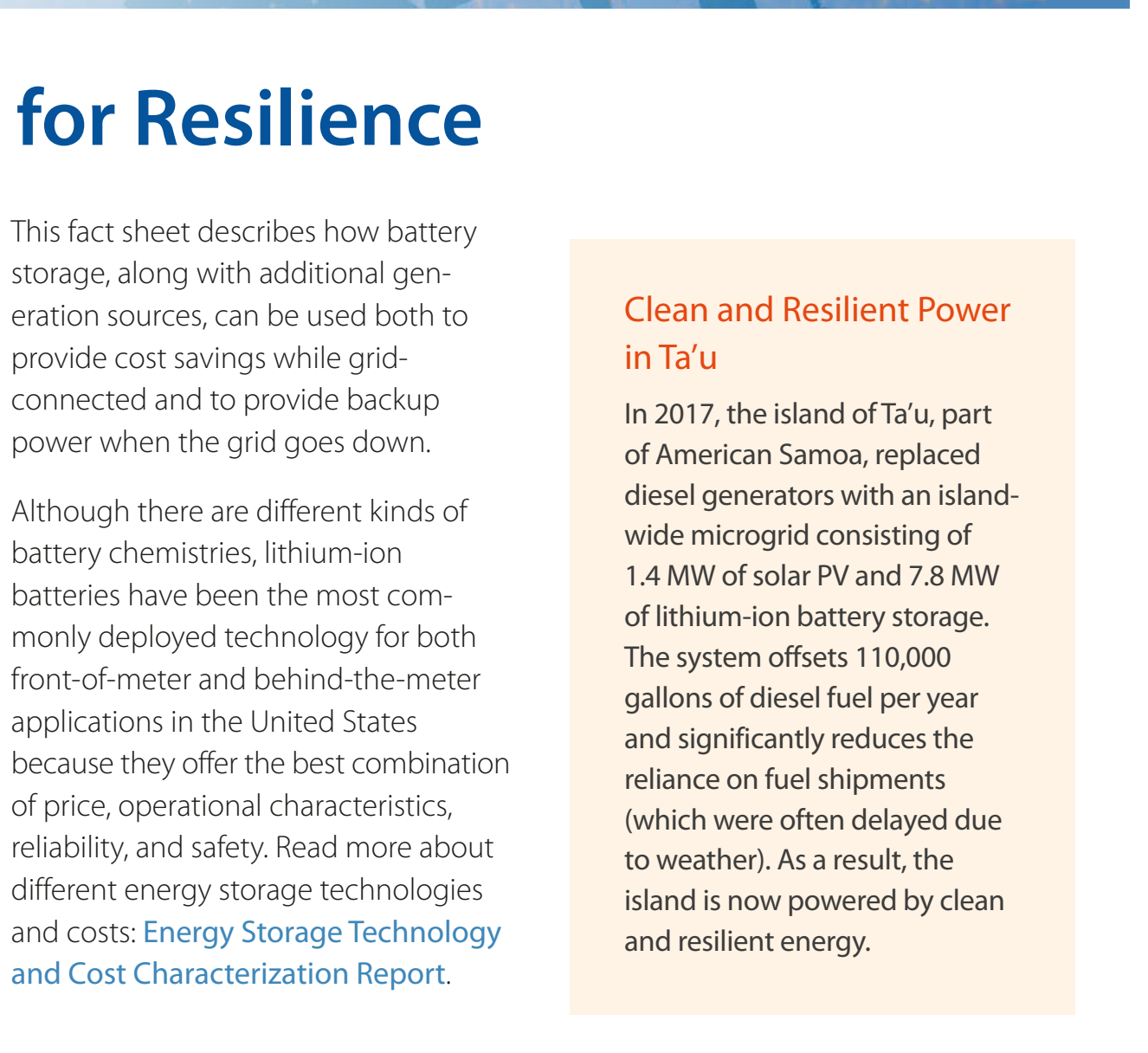

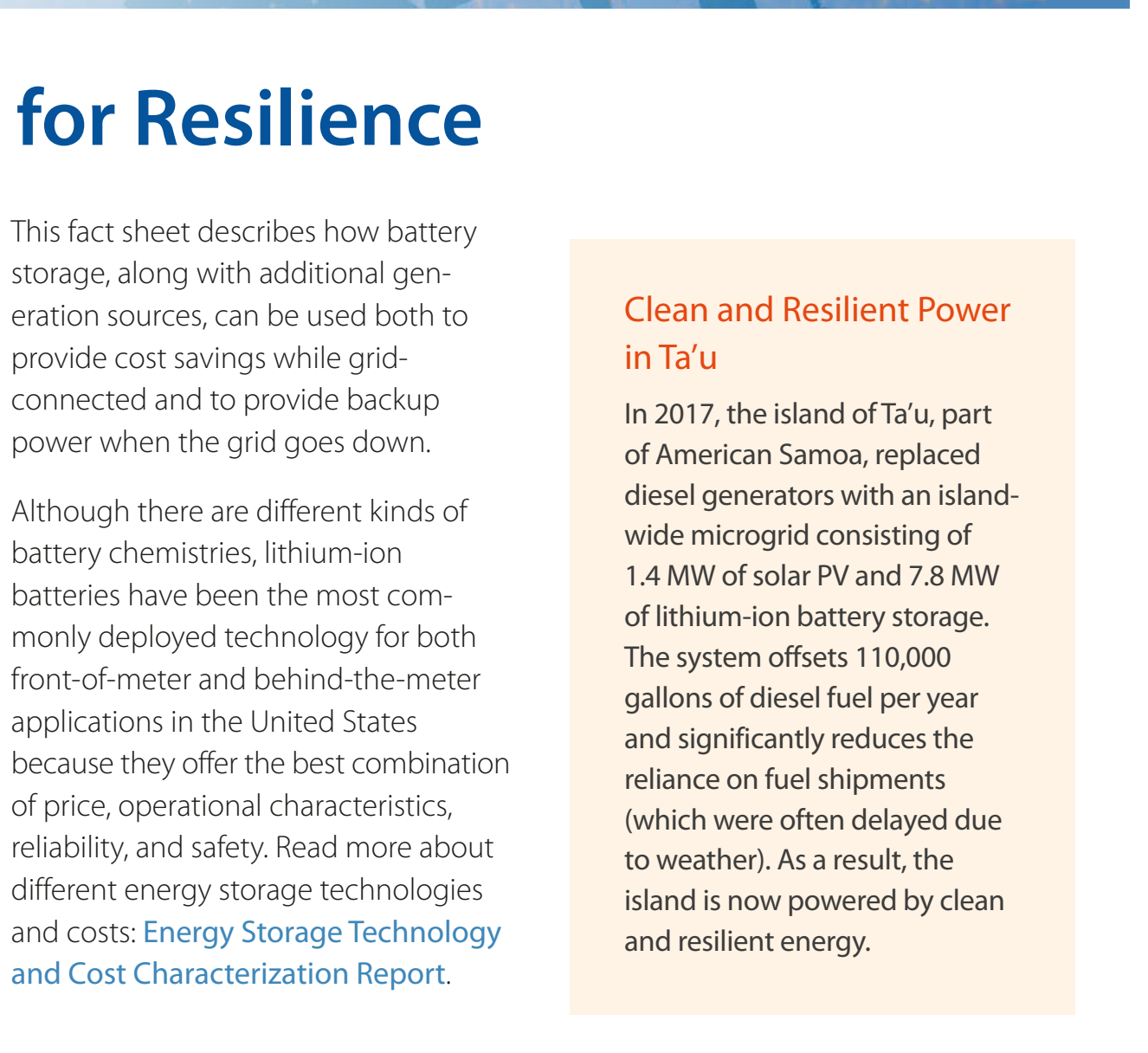

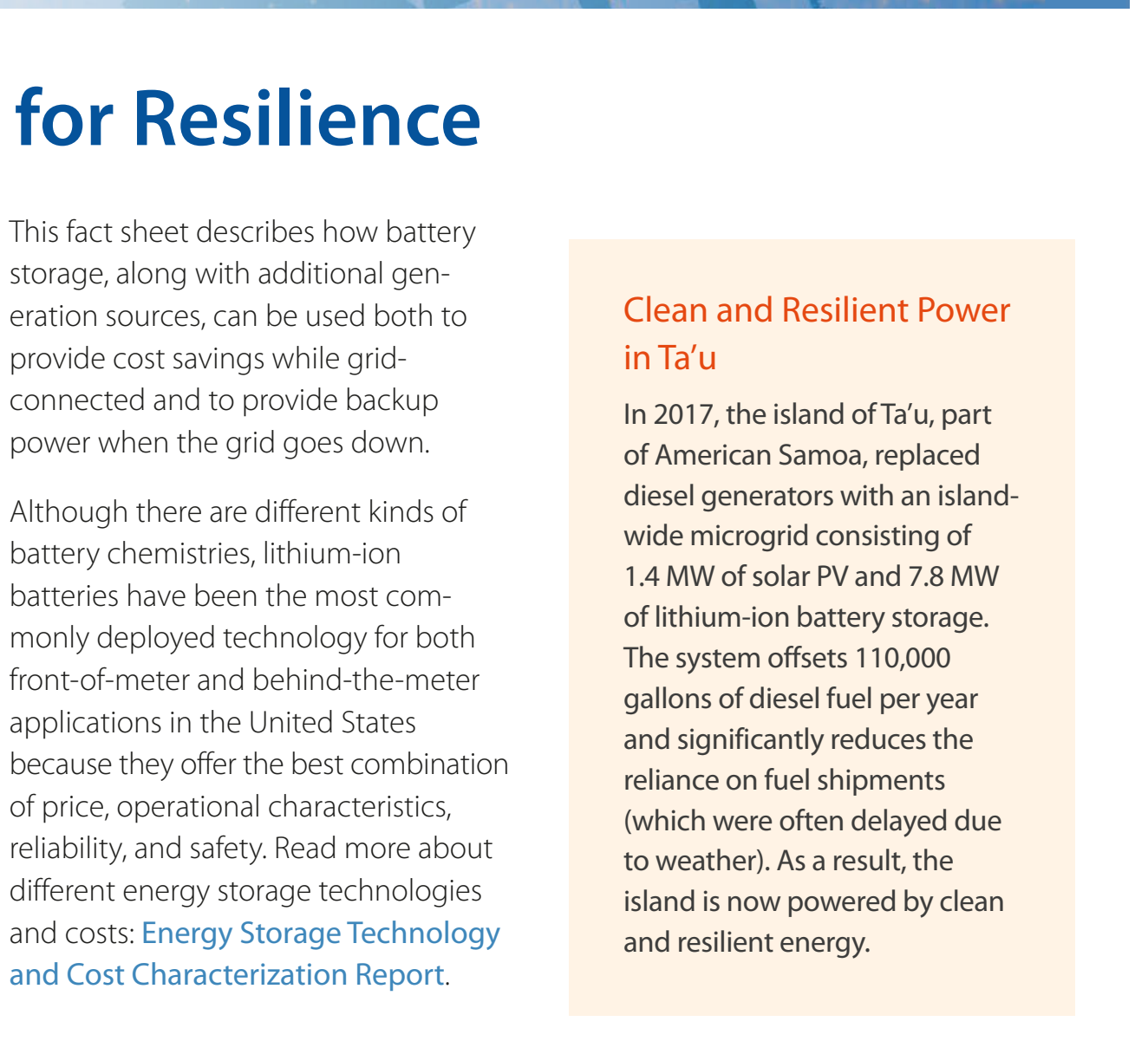

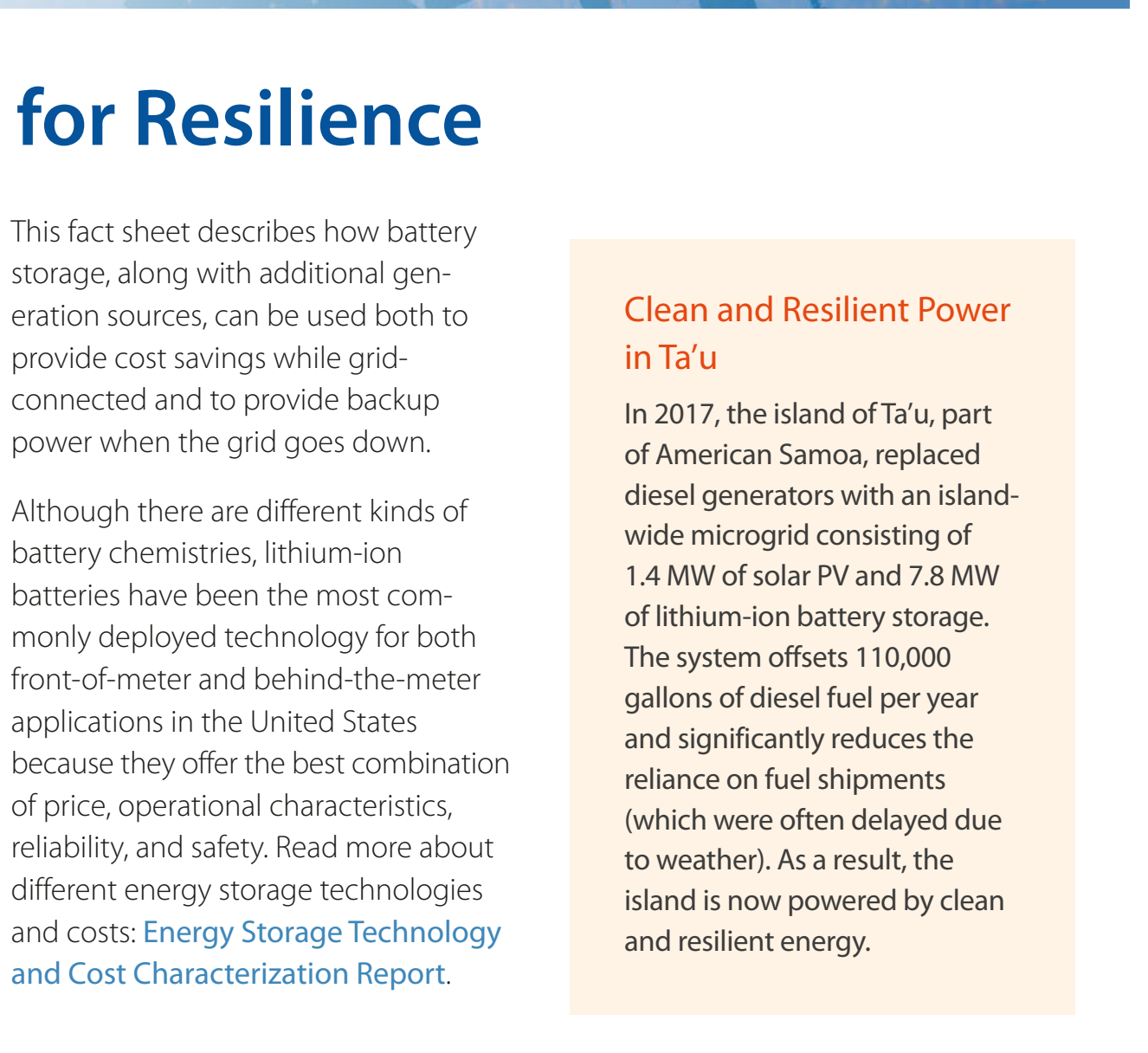

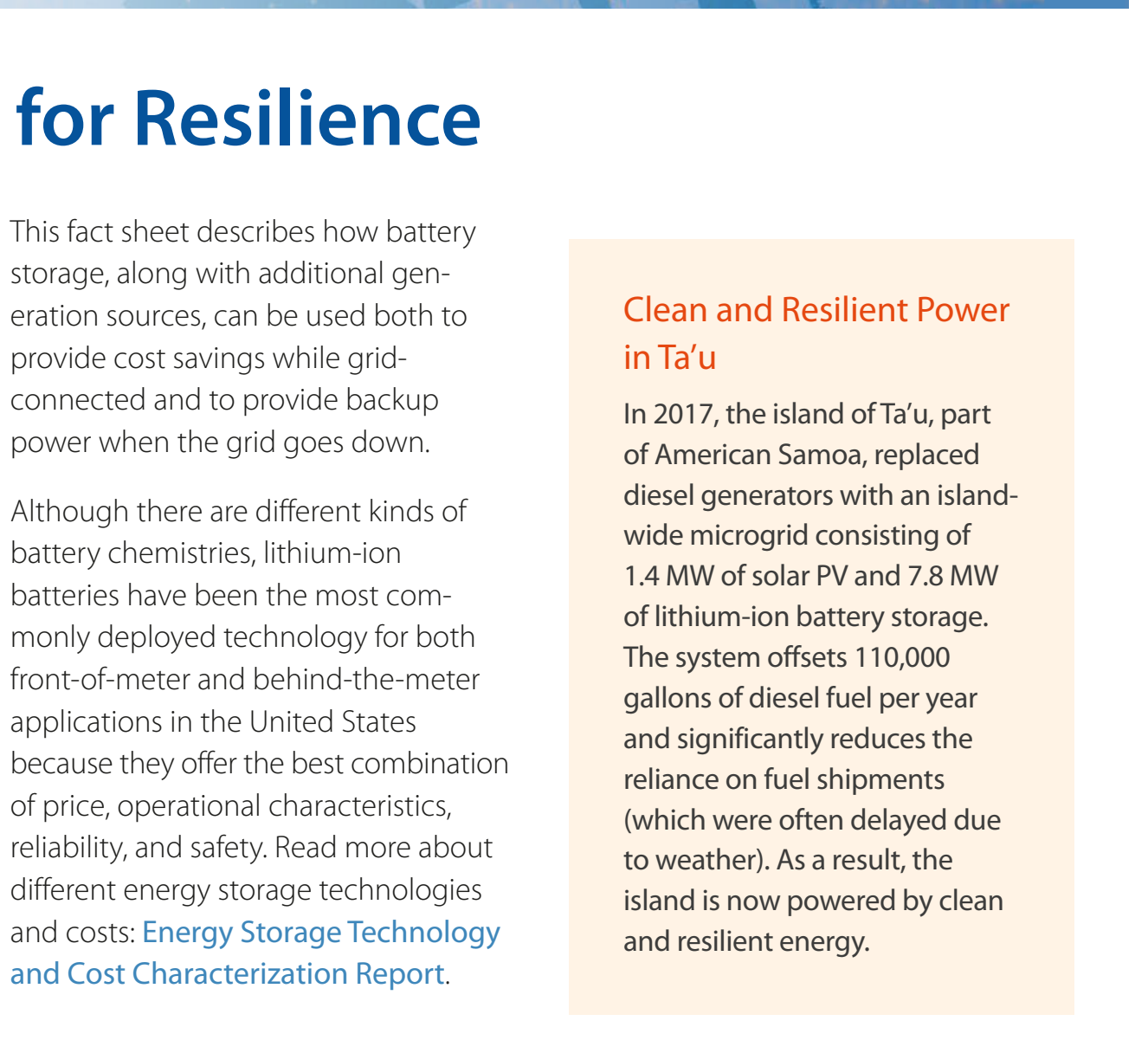

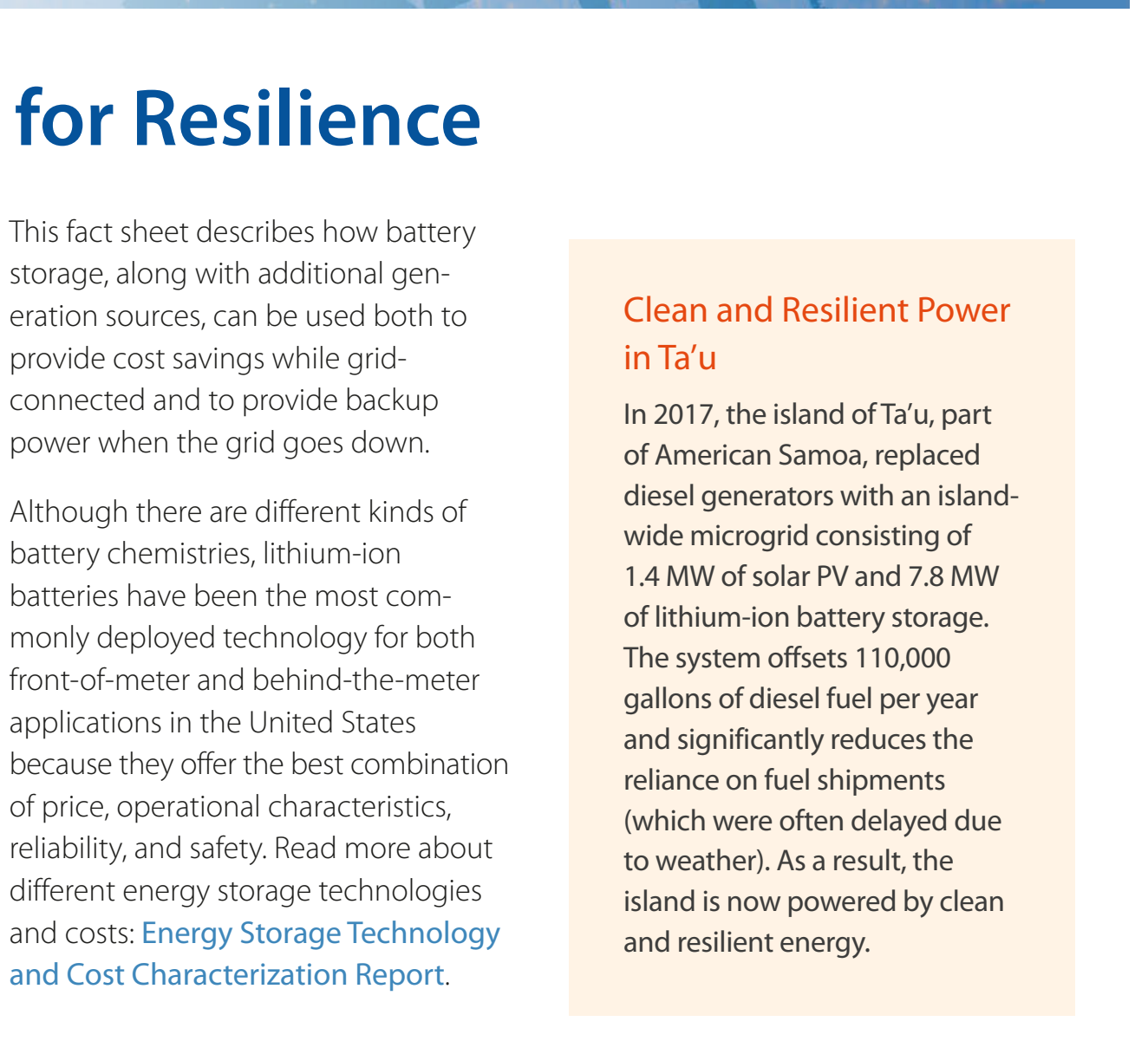

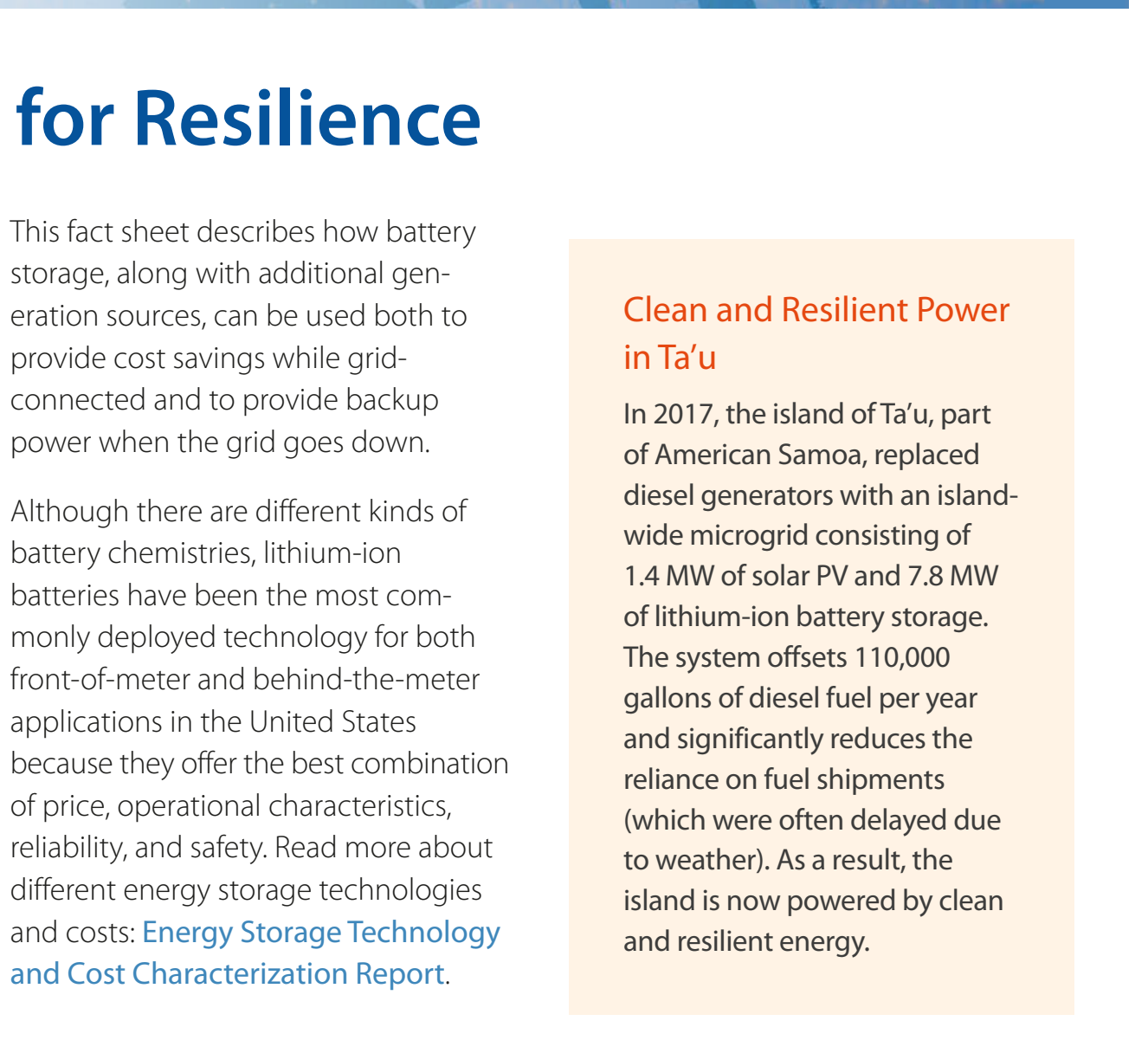

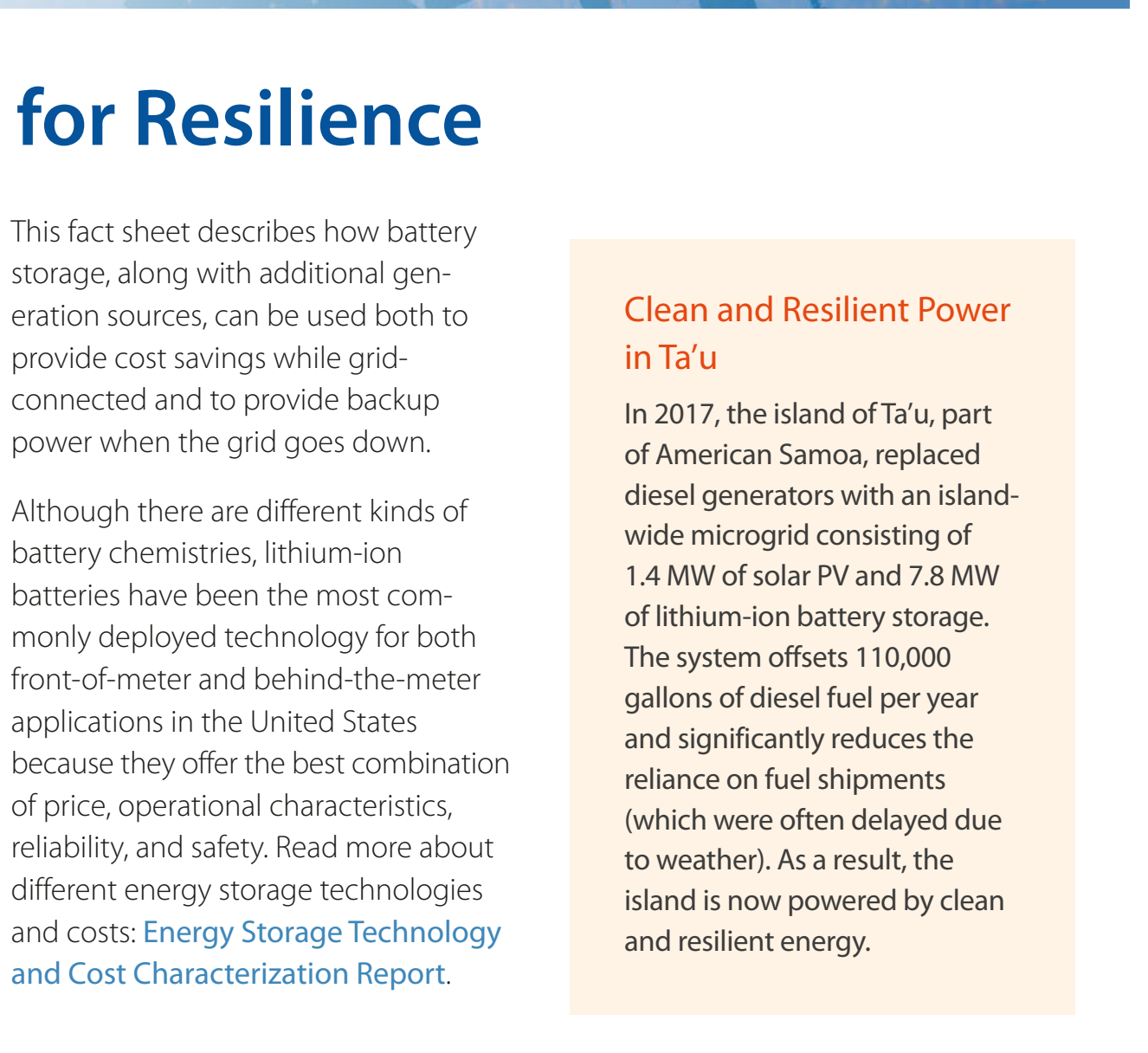

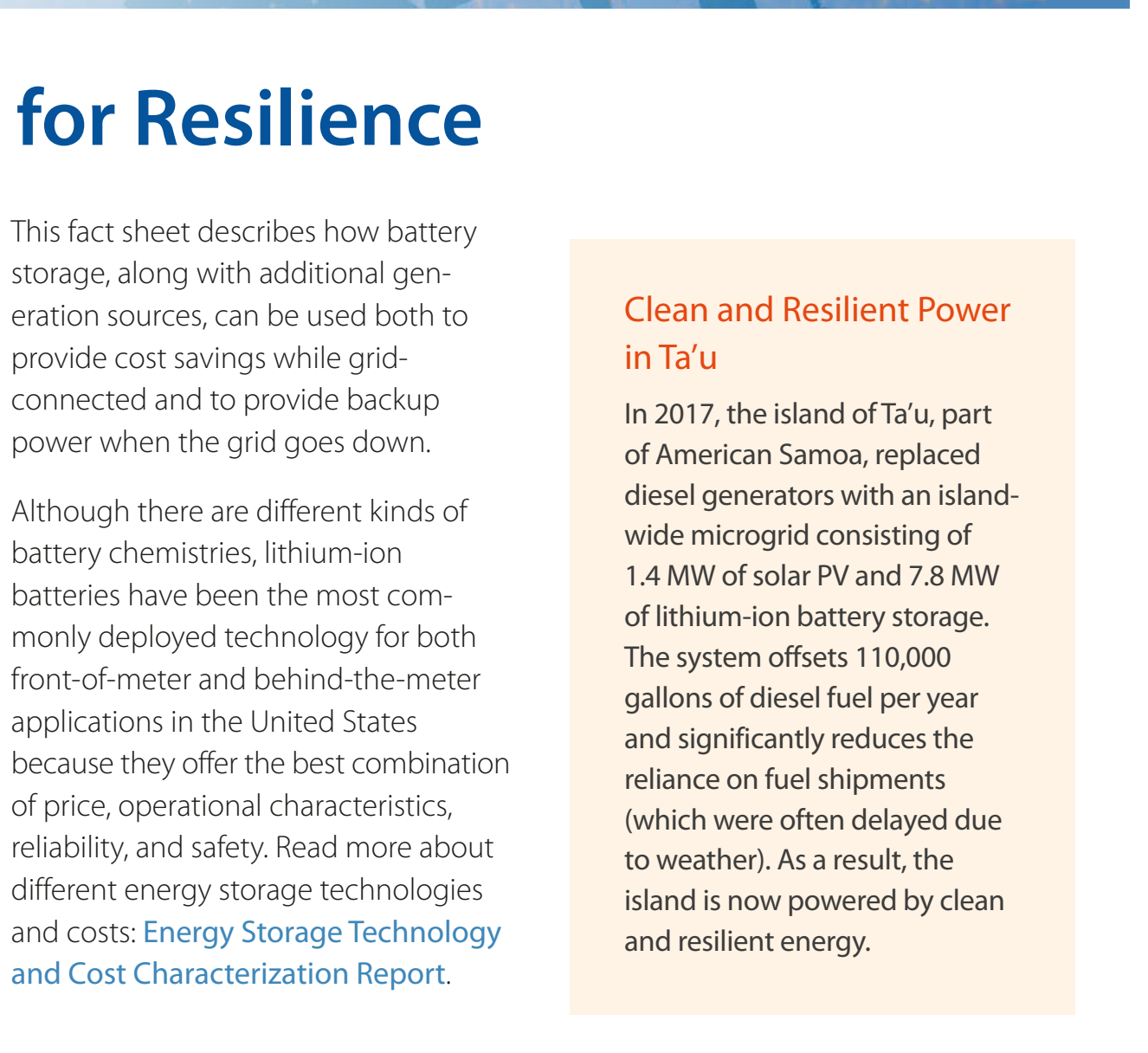

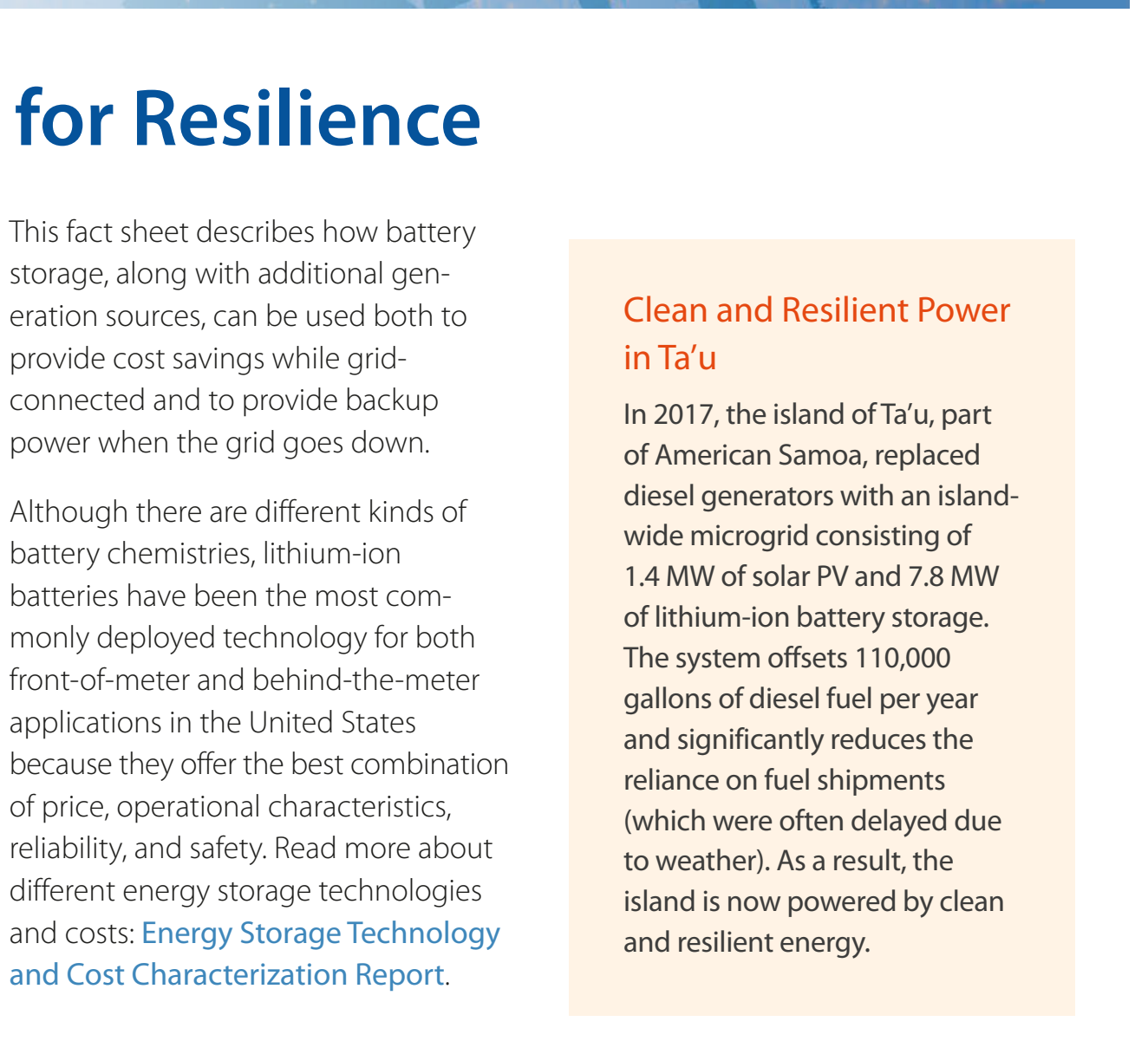

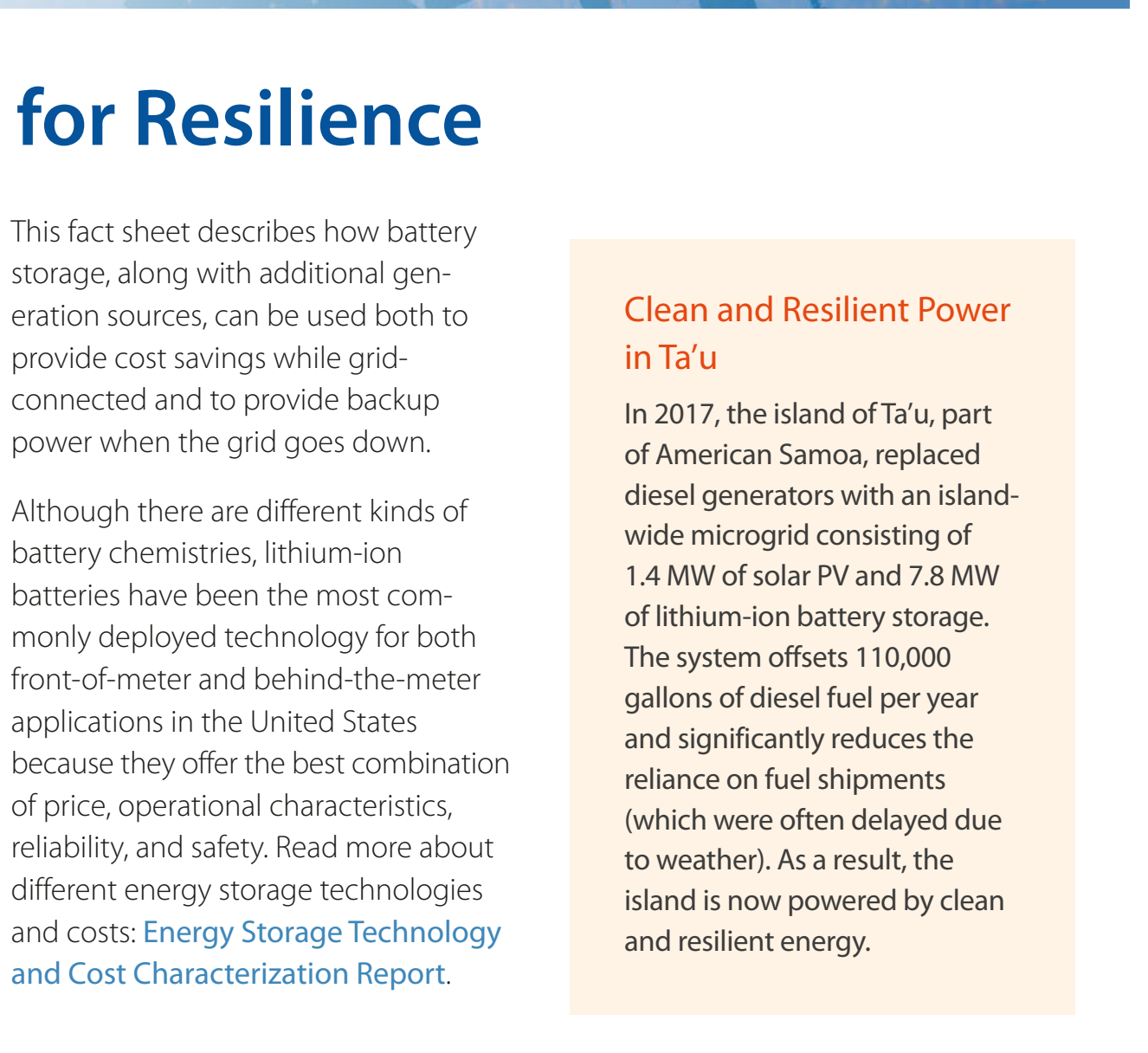

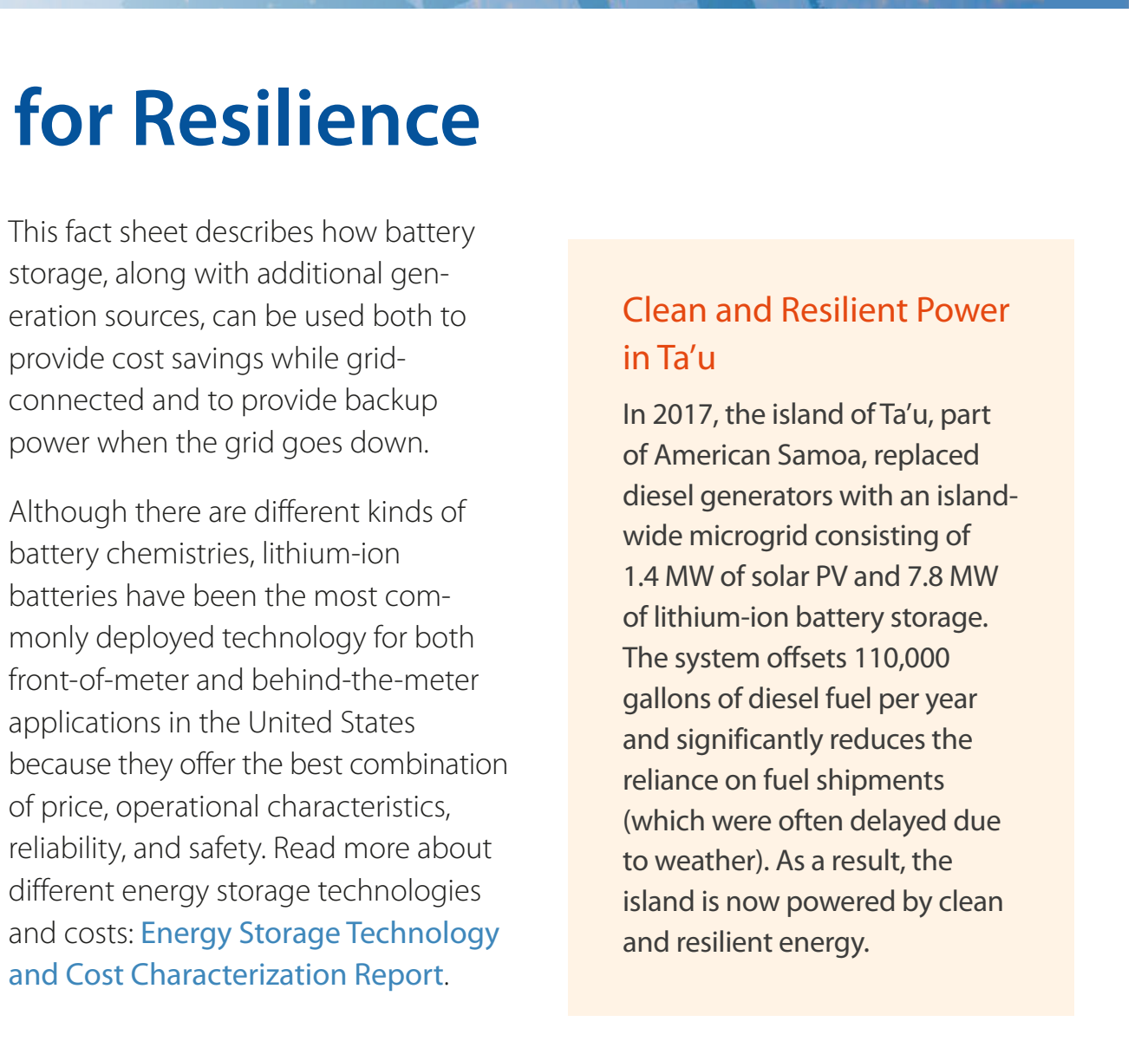

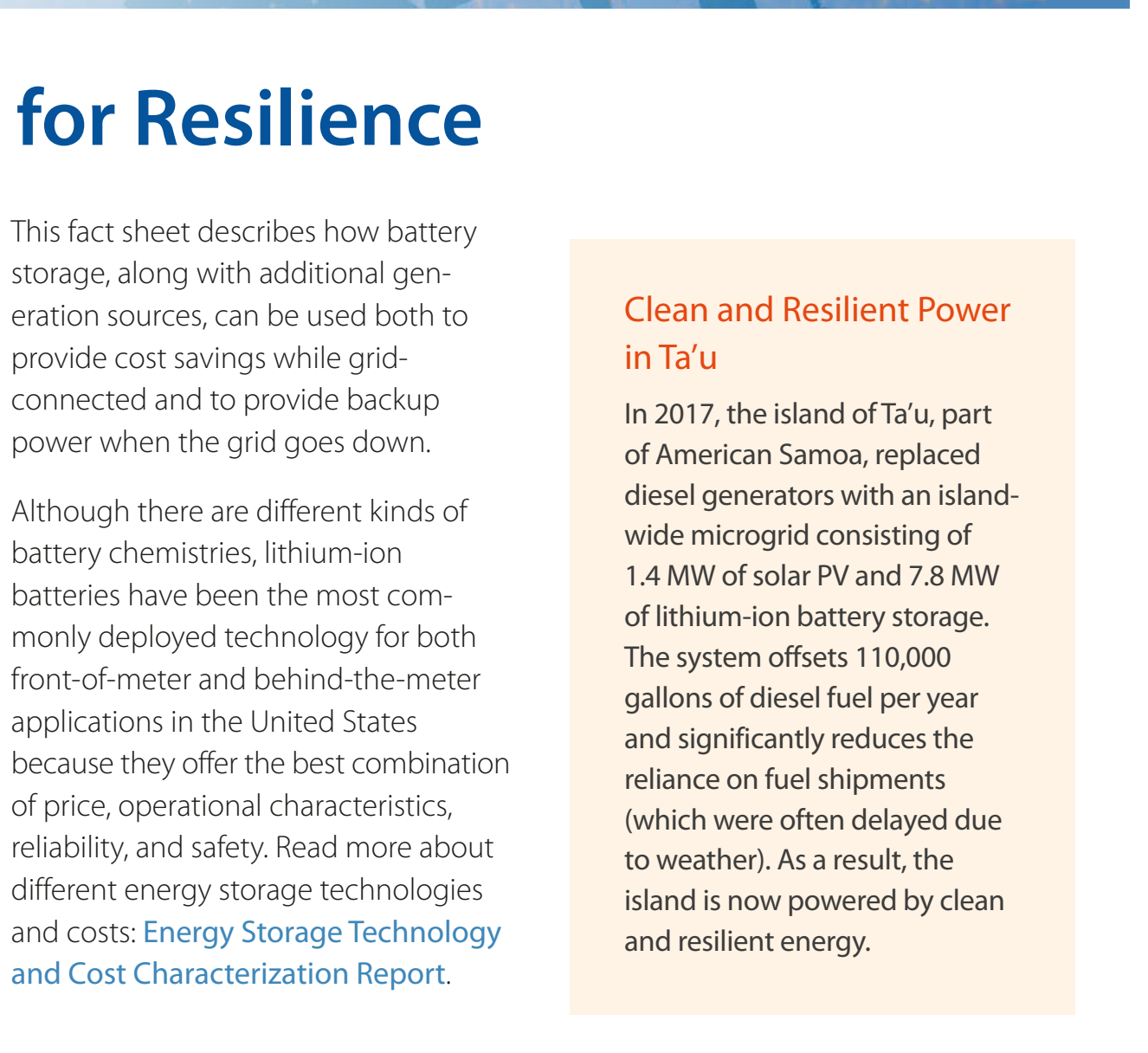

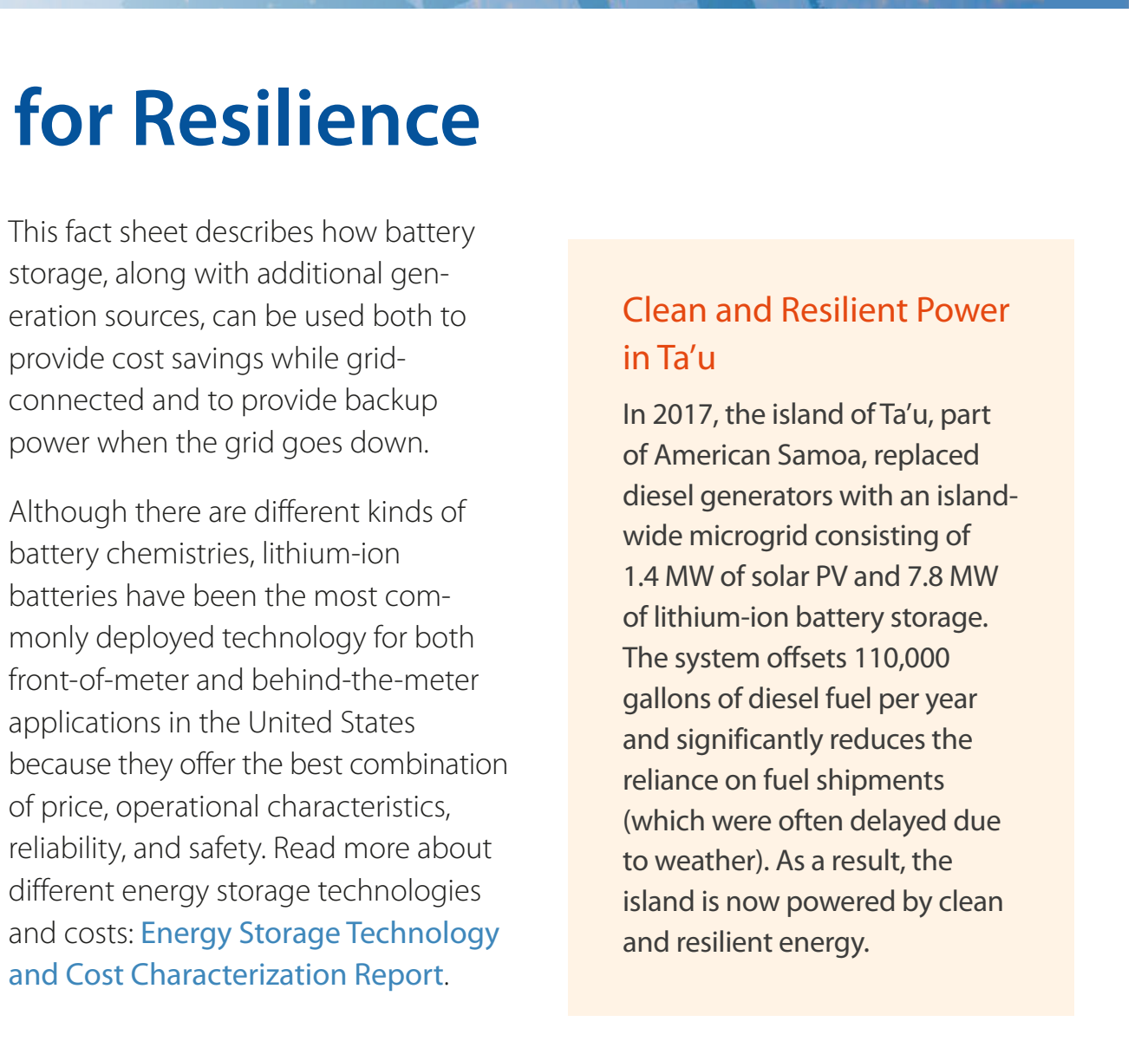

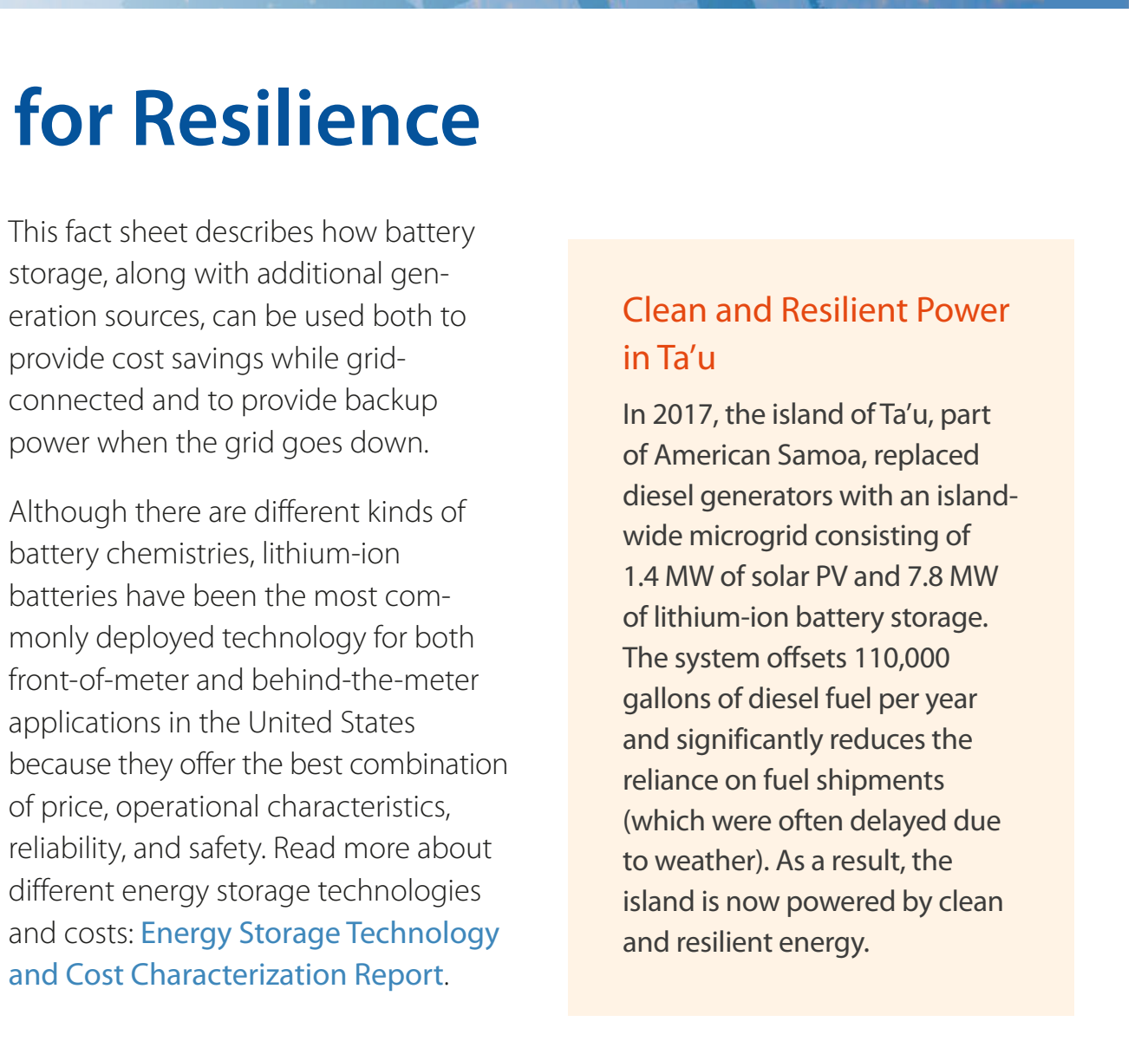

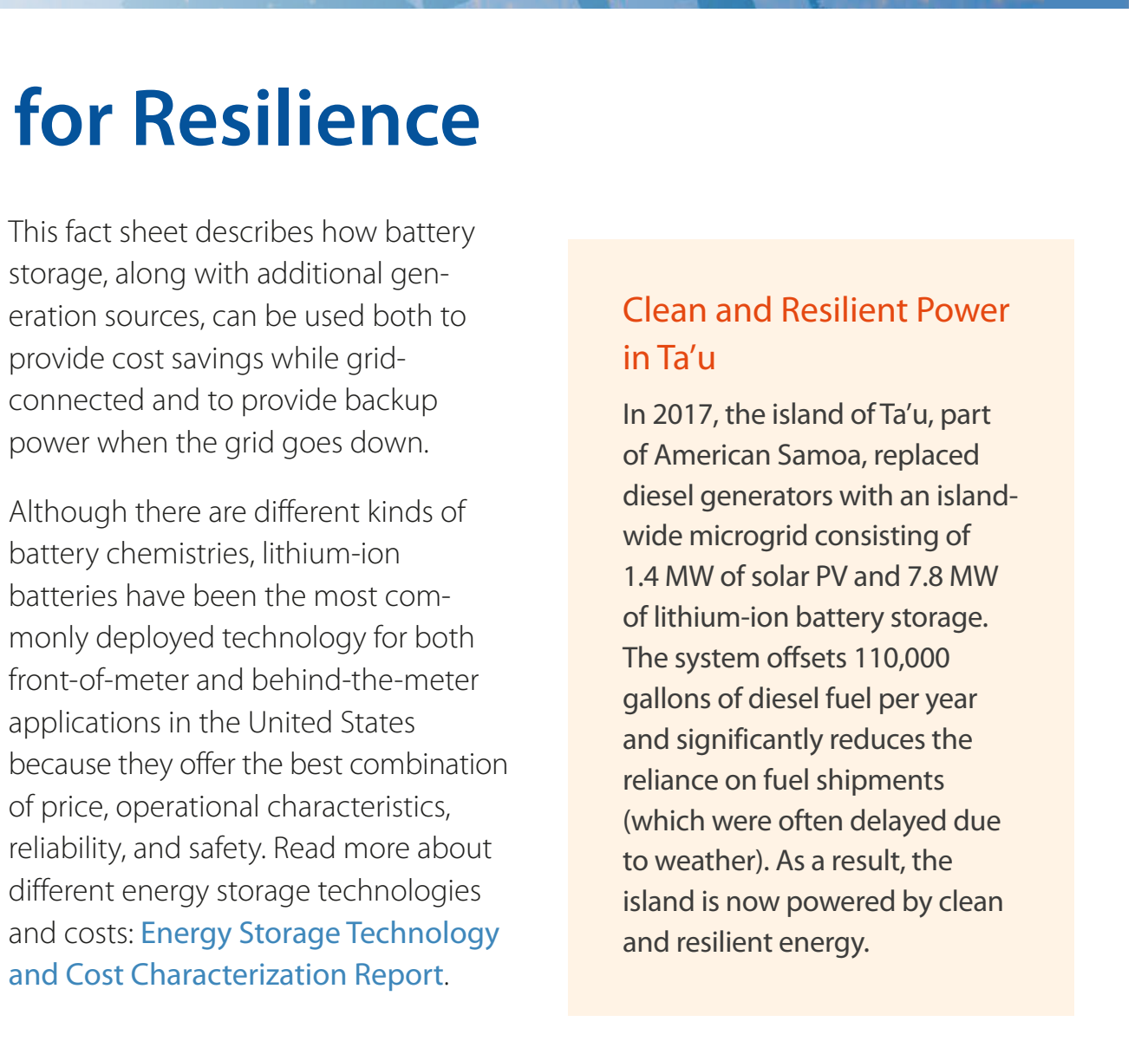

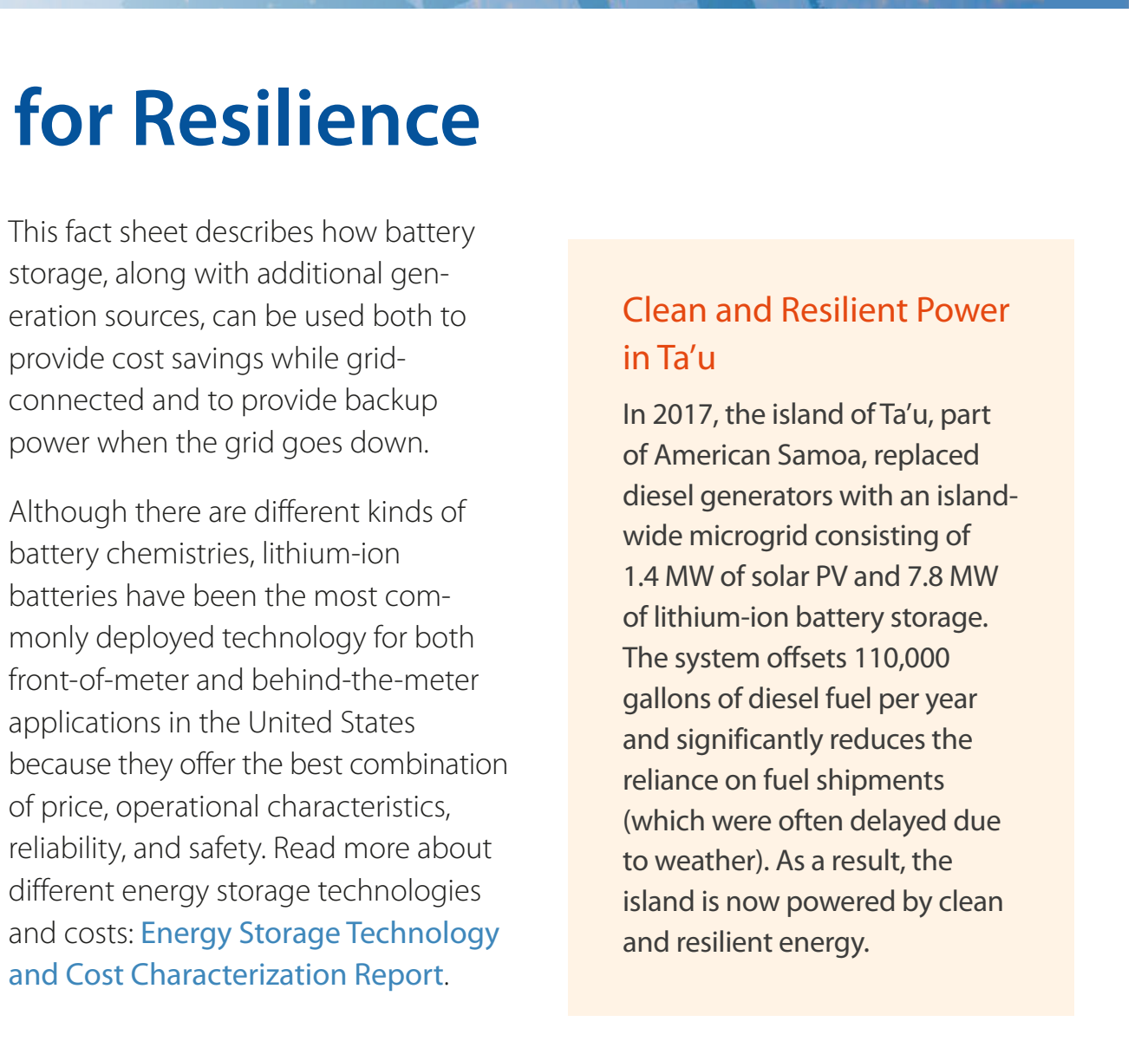

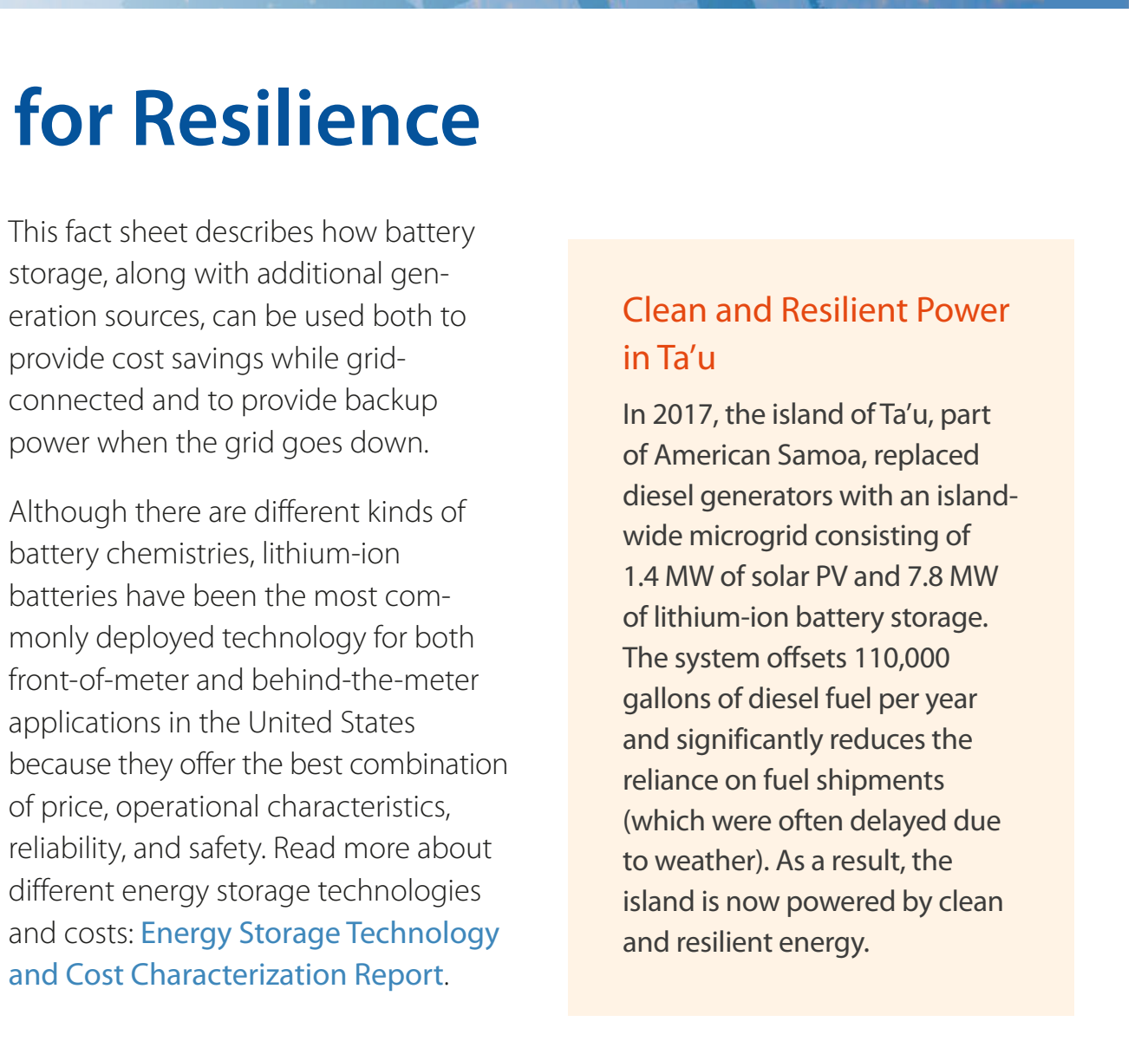

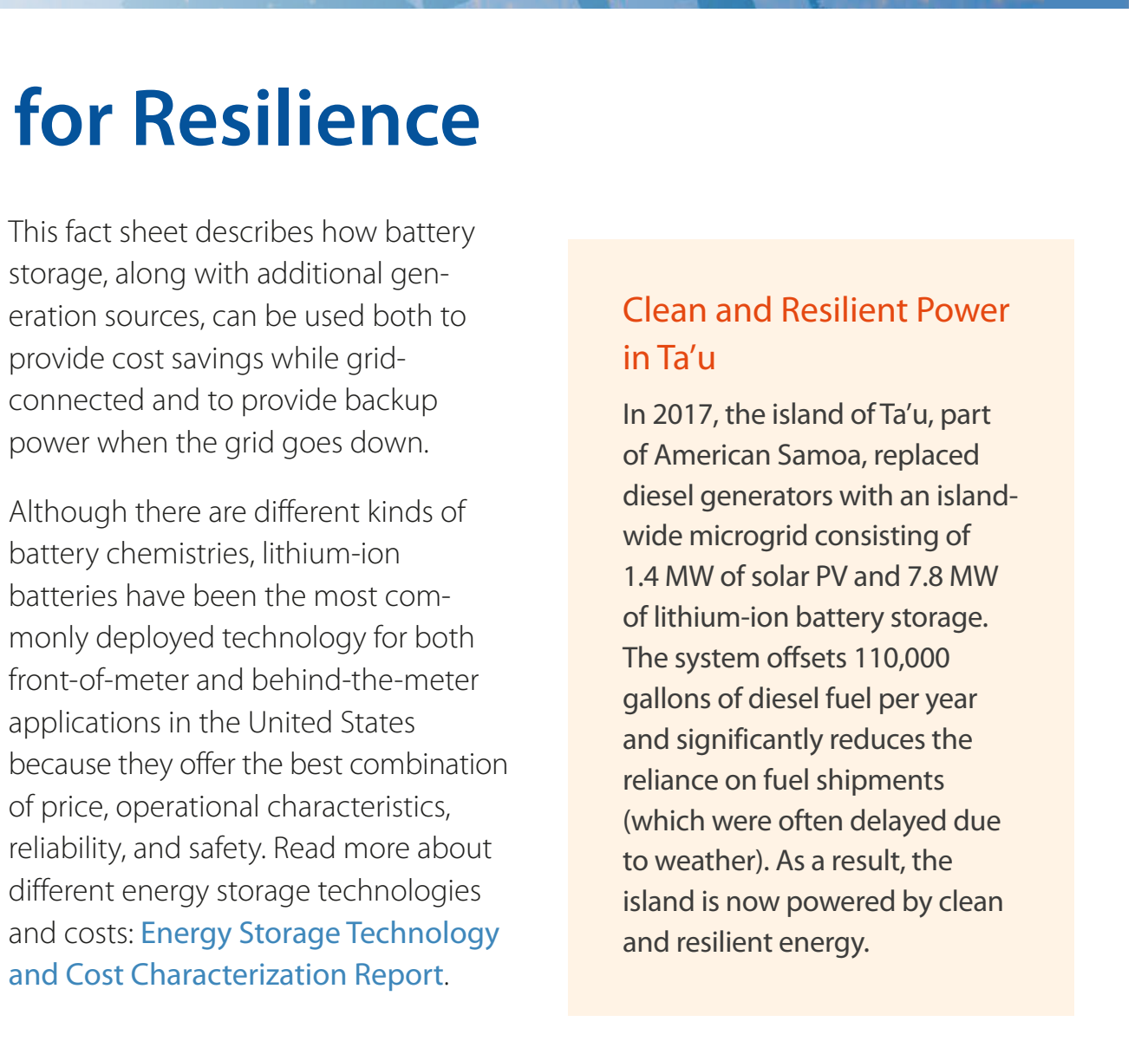

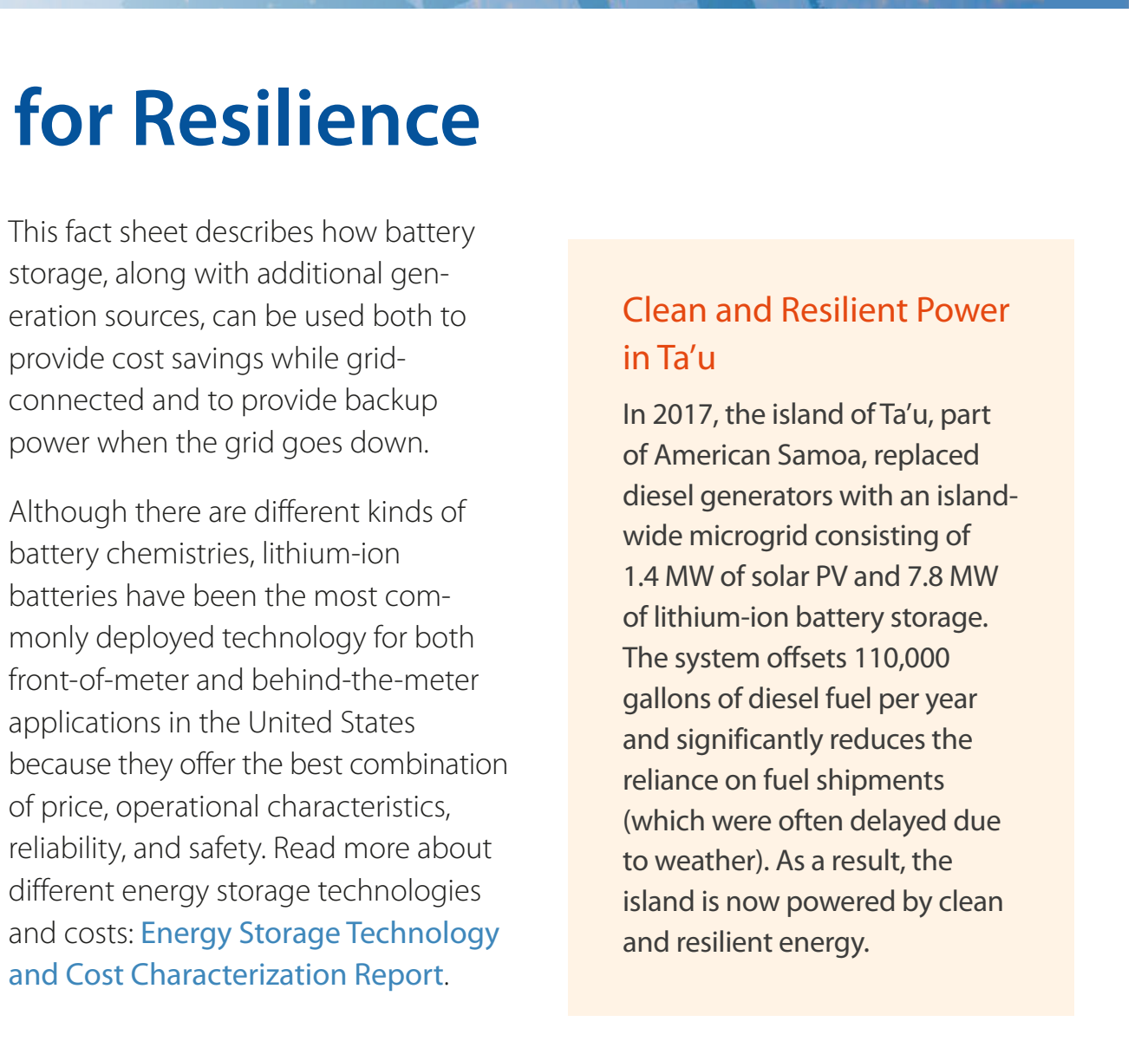

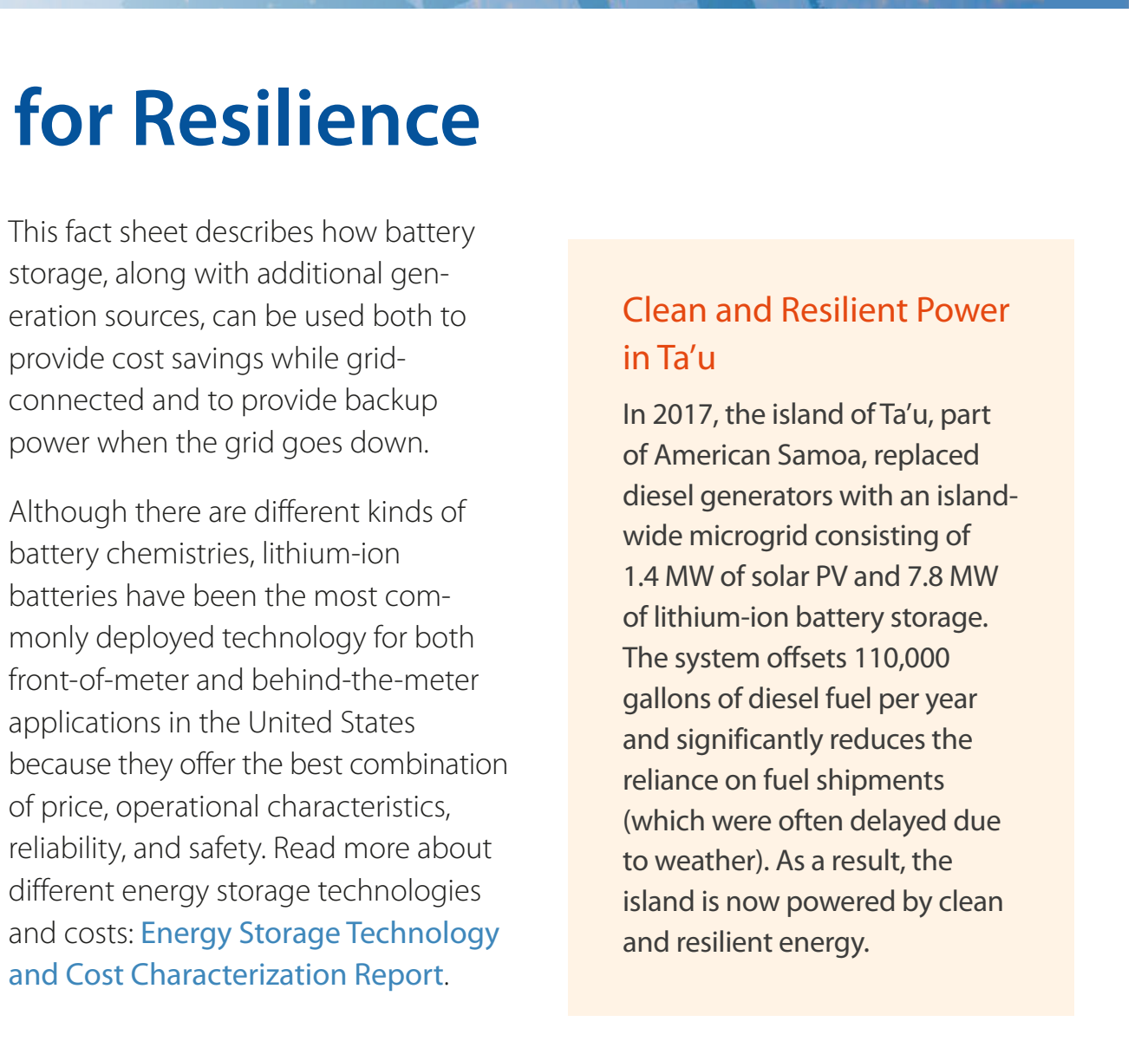

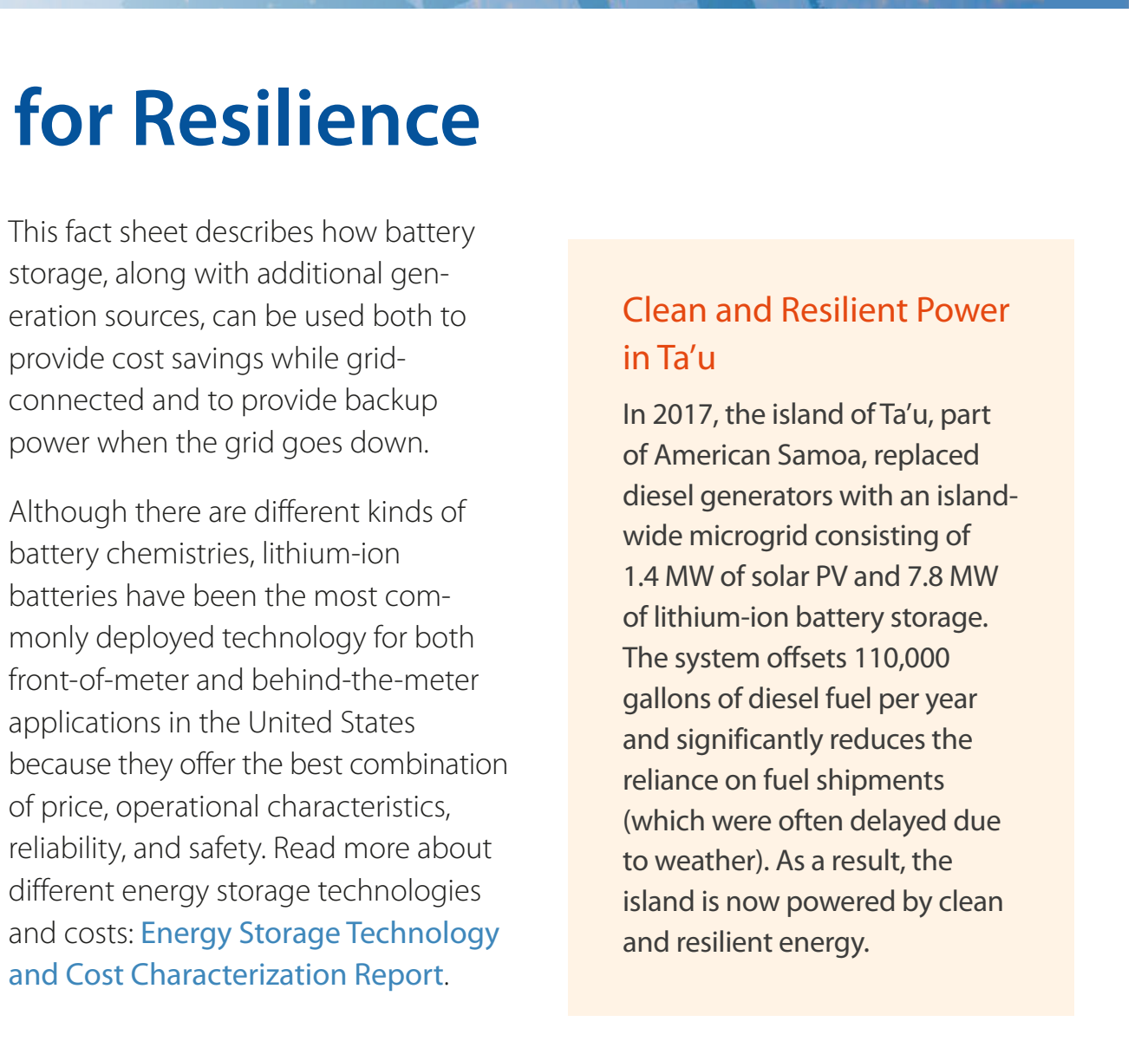

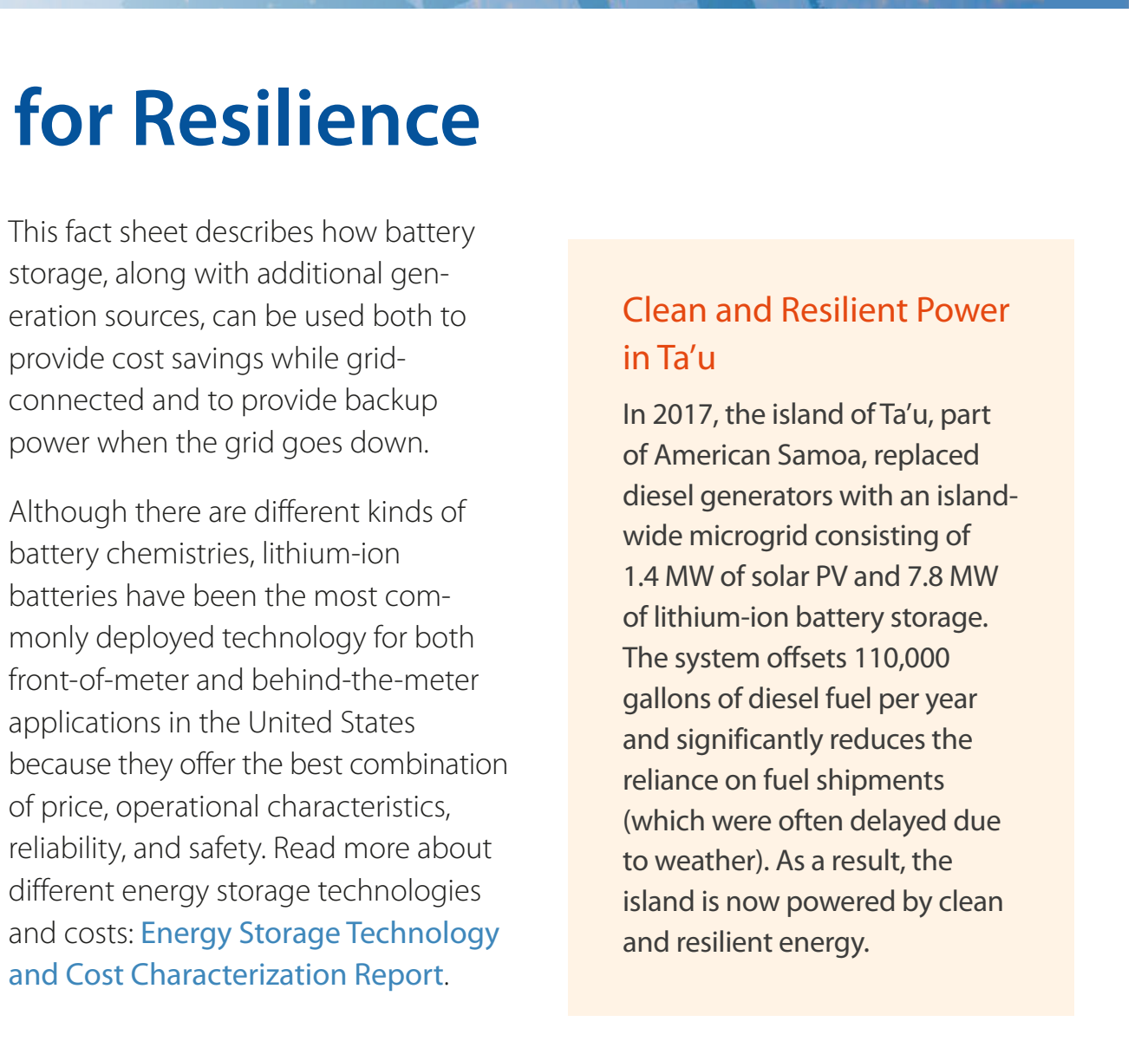

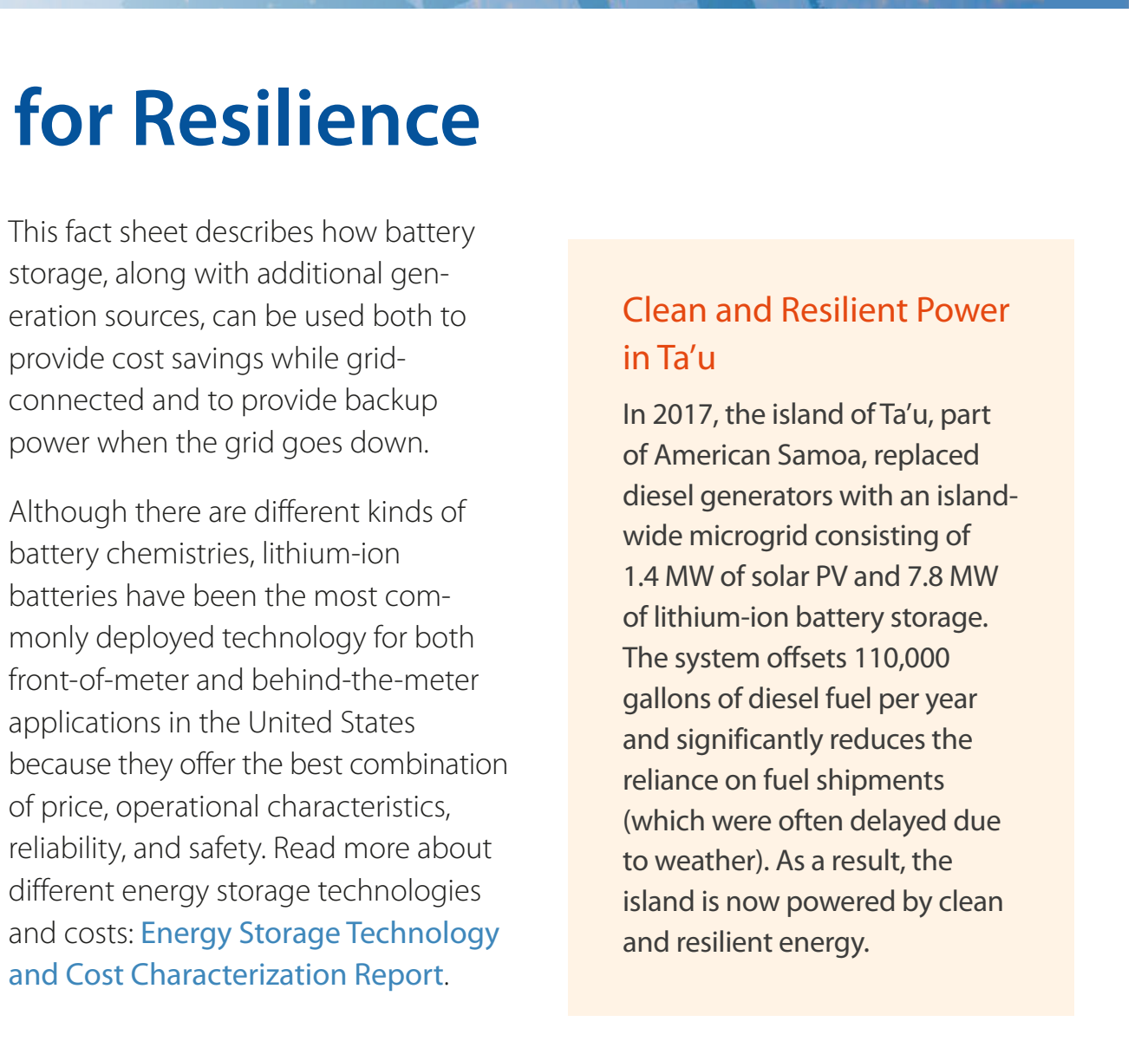

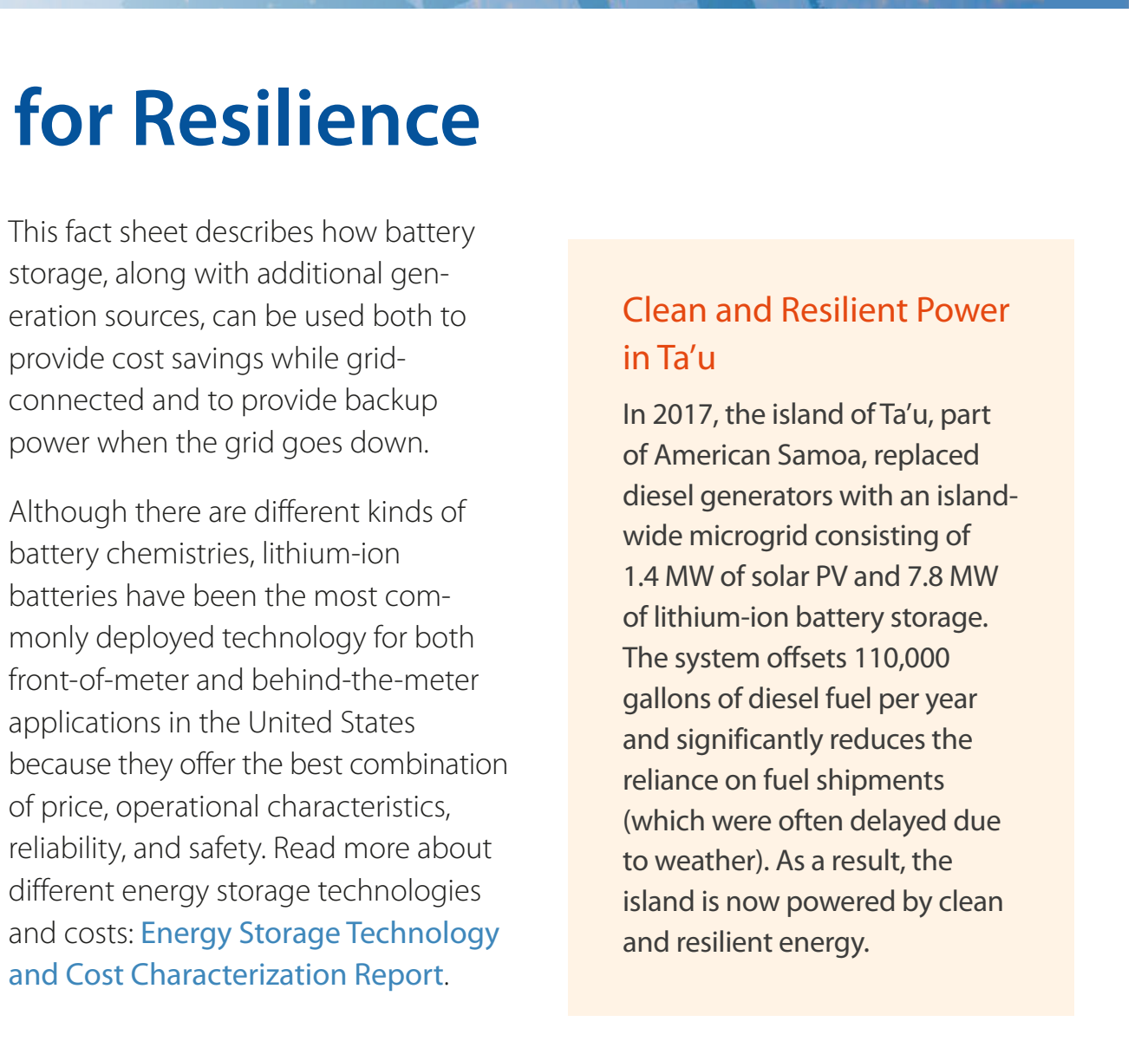

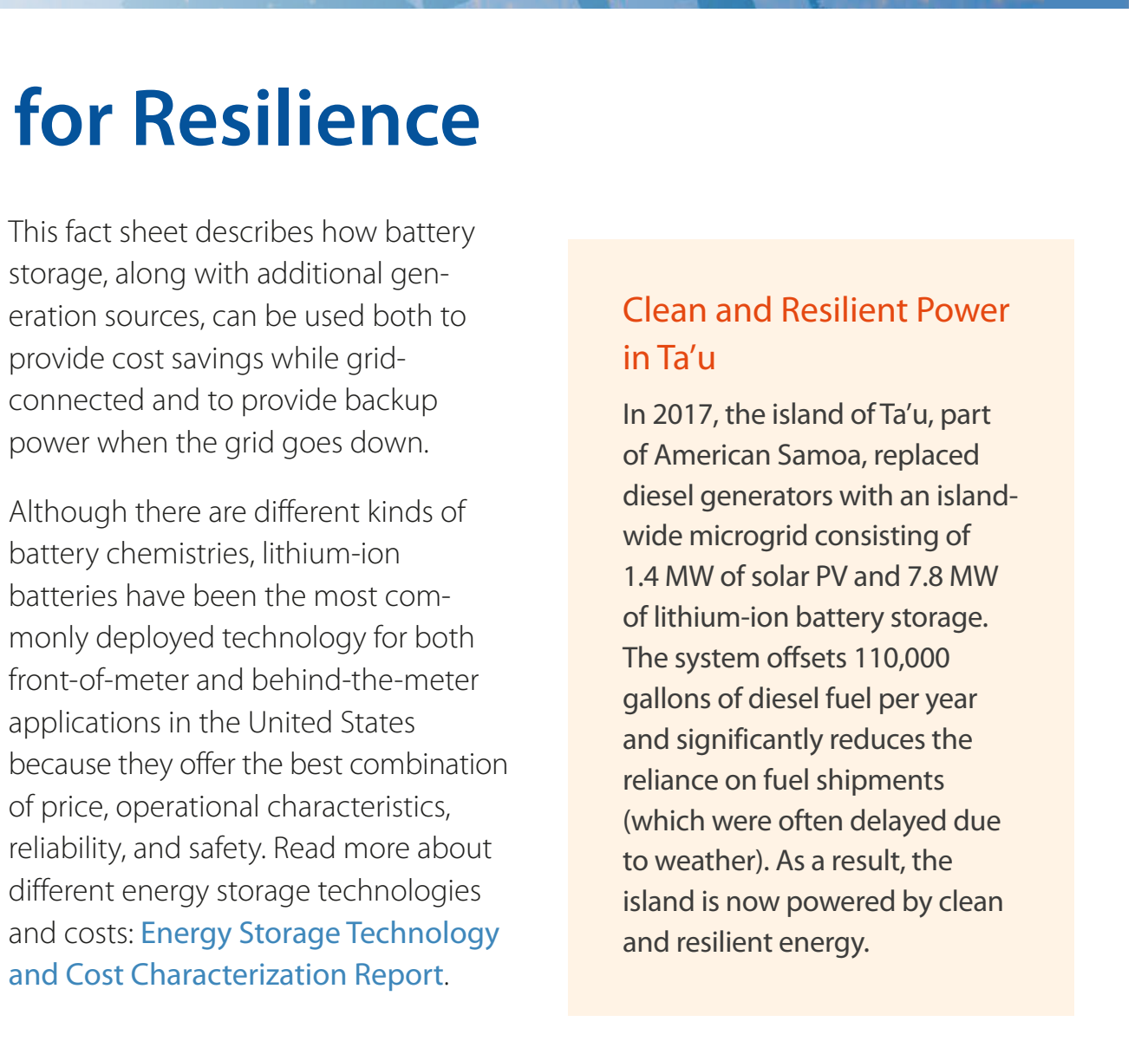

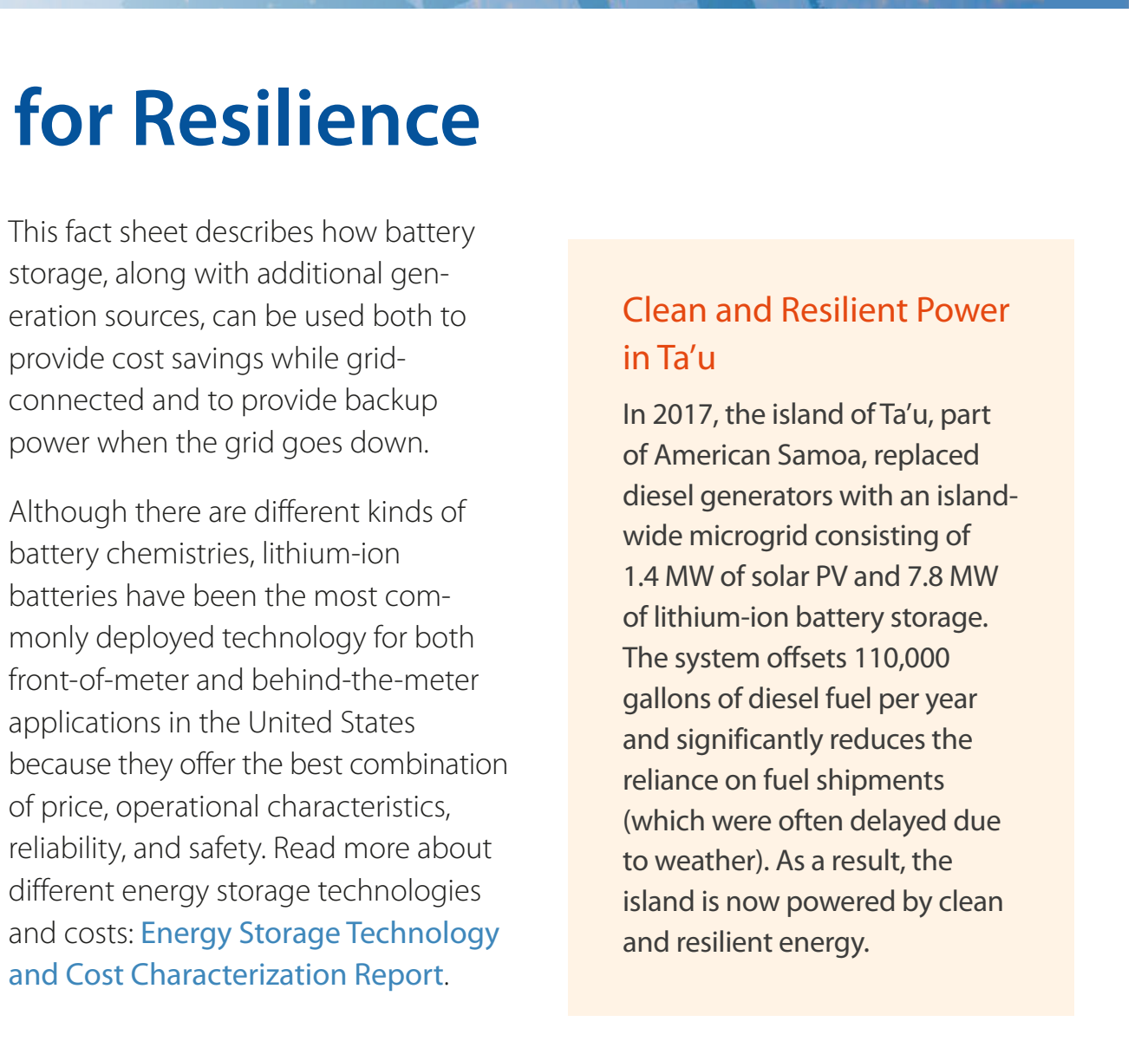

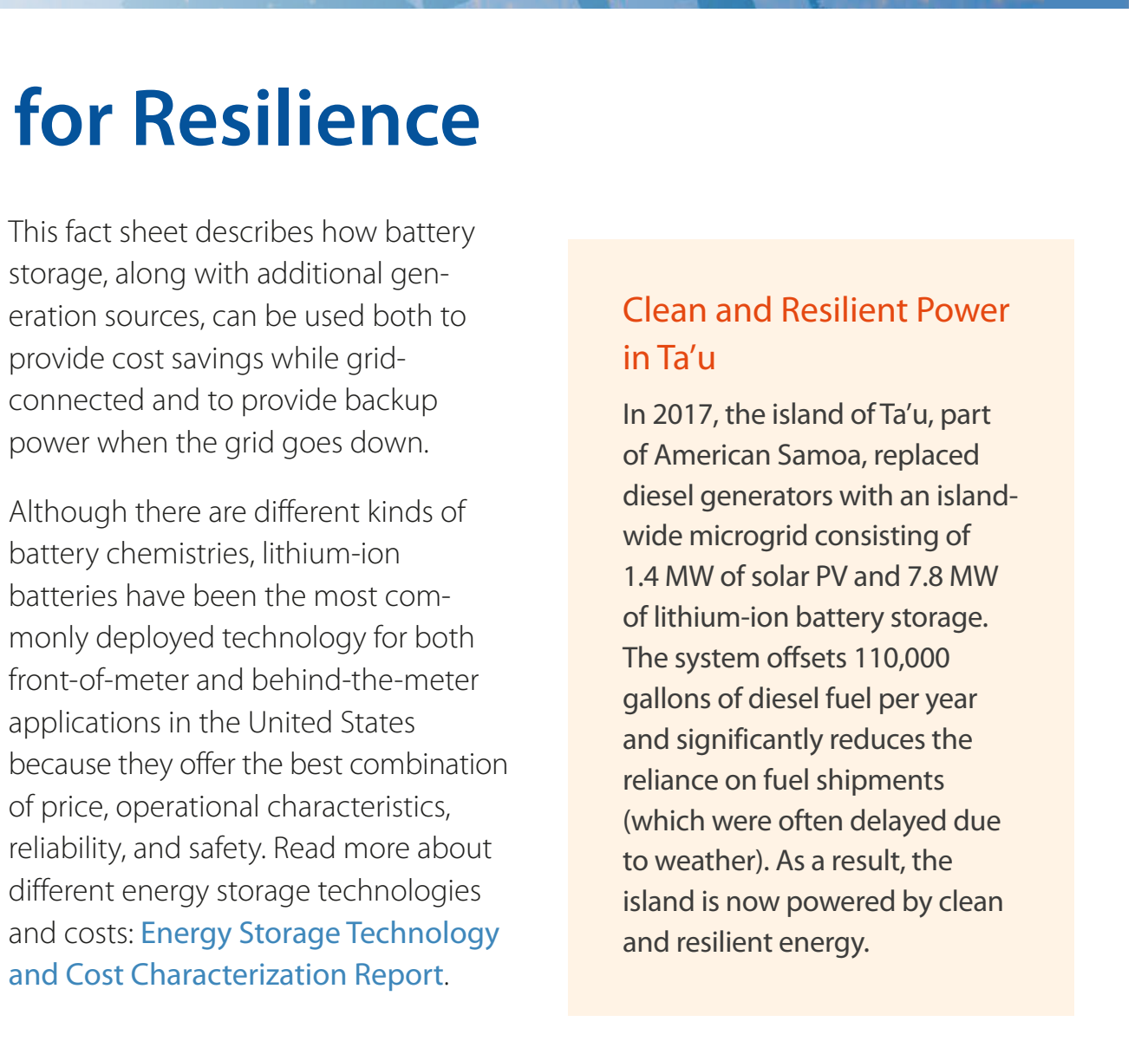

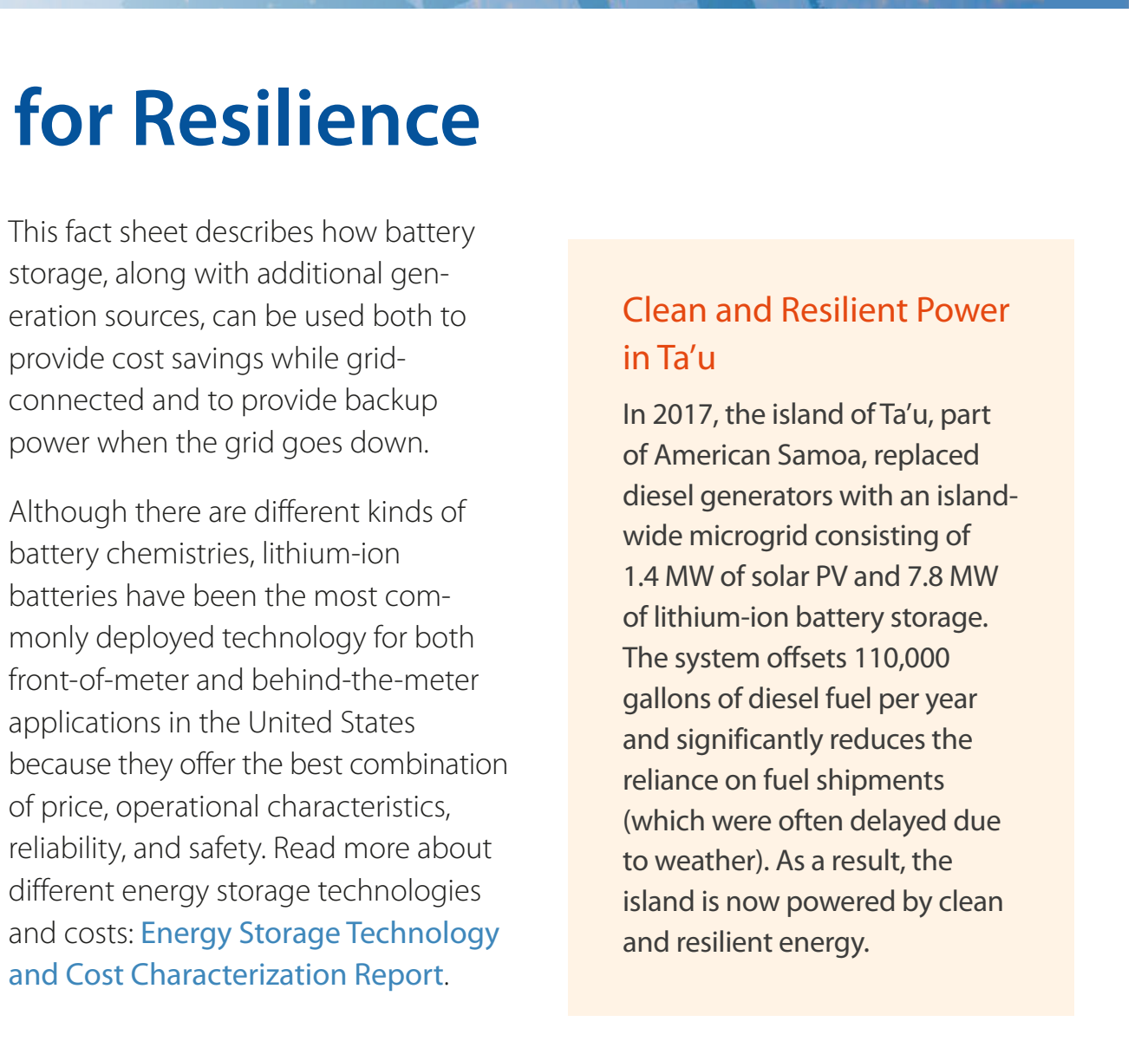

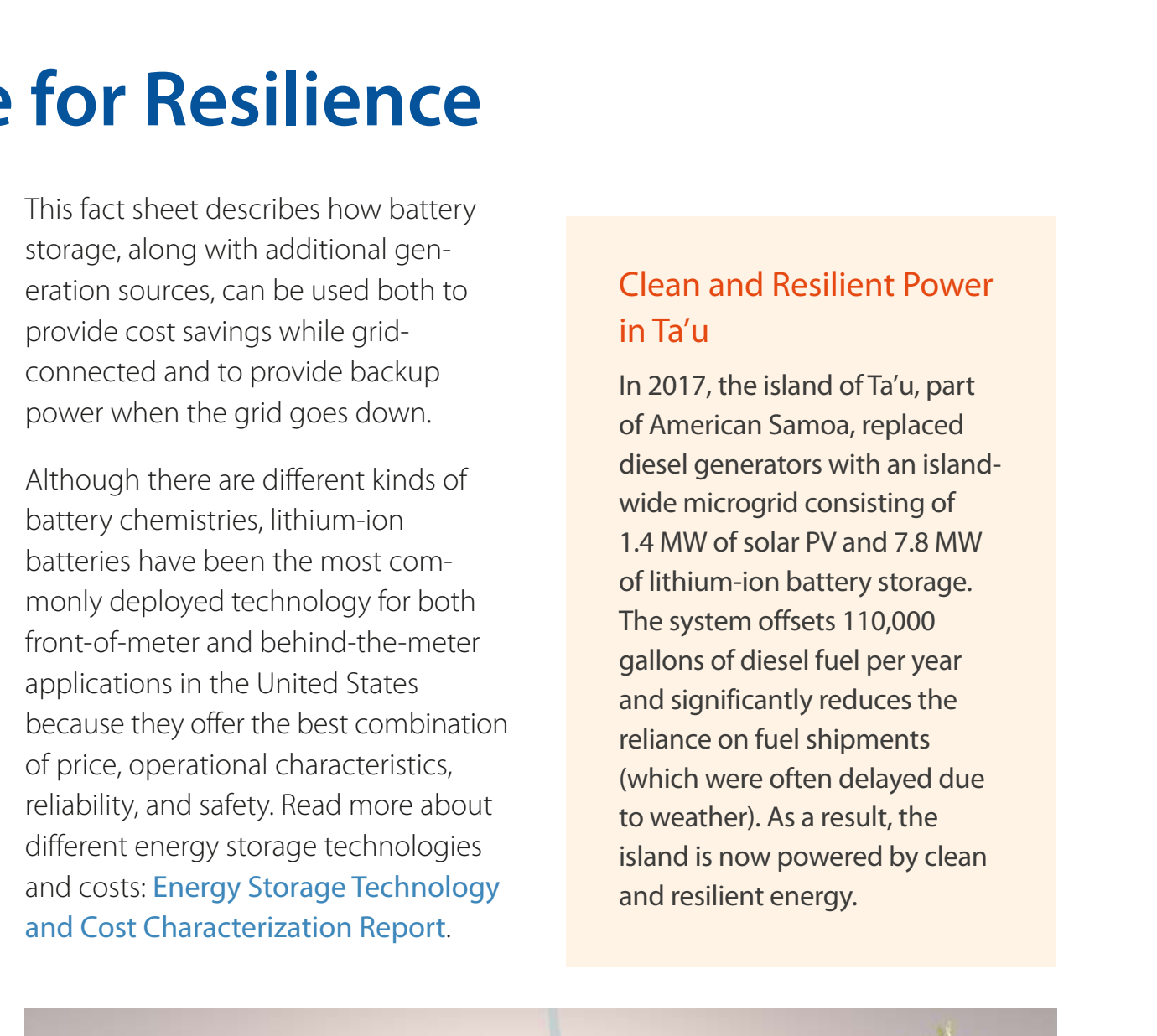

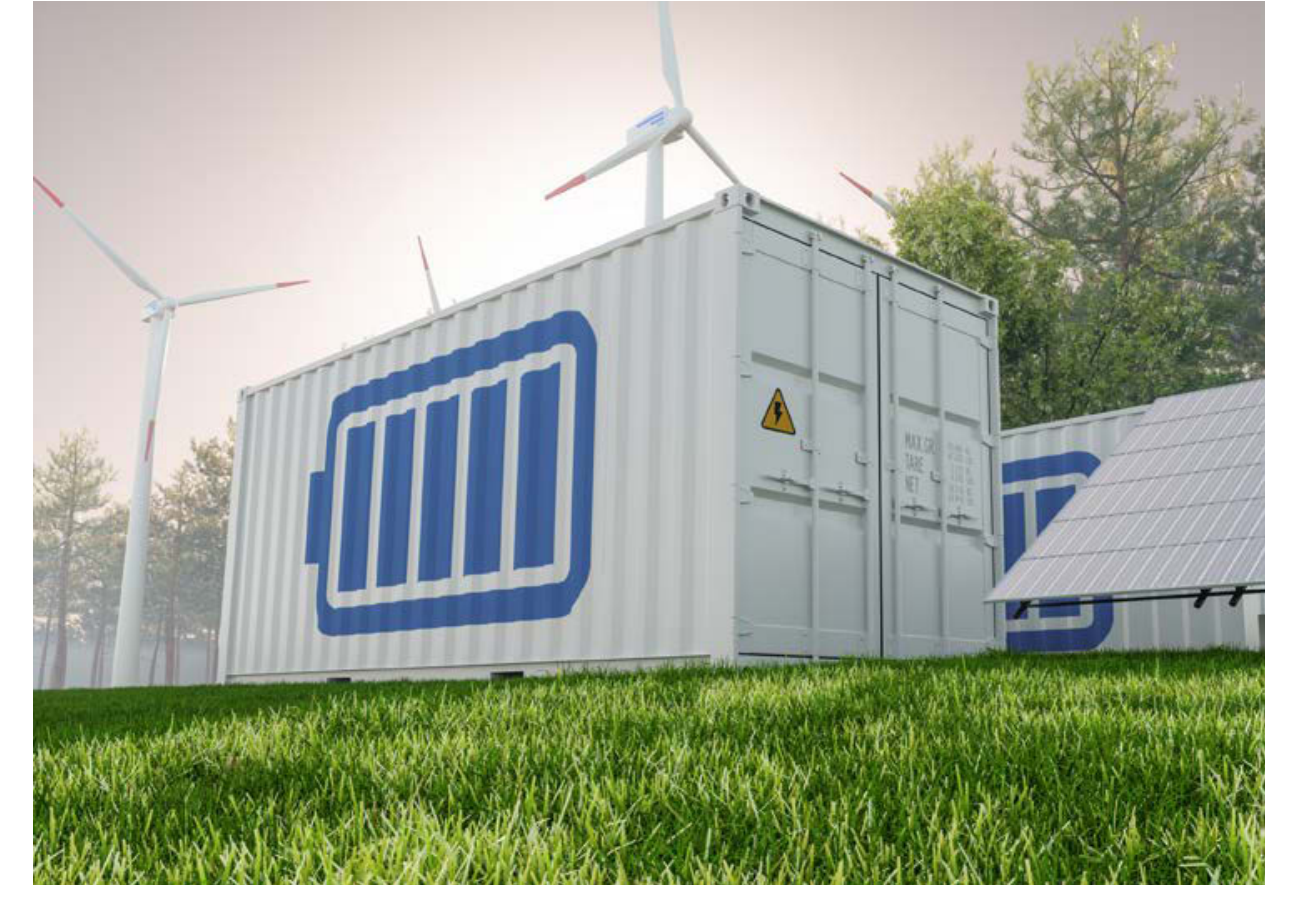

A growing number of institutions are deploying battery storage systems as a resilient energy solution. Photo from iStock 1257524754 
Table 1. Use Cases for Customer-Sited Battery Storage Systems

\begin{tabular}{|c|c|c|c|c|}
\hline Battery Use Case & $\begin{array}{l}\text { Uninterruptable Power } \\
\text { Source }\end{array}$ & Off-Grid & $\begin{array}{l}\text { Grid-Connected } \\
\text { Islandable }\end{array}$ & On-Site Hosting \\
\hline Description & $\begin{array}{l}\text { Battery backup ready to be } \\
\text { discharged }\end{array}$ & $\begin{array}{l}\text { Providing continuous } \\
\text { power in lieu of utility grid }\end{array}$ & $\begin{array}{l}\text { Lowering cost of utility } \\
\text { purchases and providing } \\
\text { backup power during grid } \\
\text { outage }\end{array}$ & $\begin{array}{l}\text { Hosting large-scale } \\
\text { generation for off-site sale }\end{array}$ \\
\hline Why/where it works & $\begin{array}{l}\text { Sites with critical loads that } \\
\text { have zero tolerance for } \\
\text { disruption }\end{array}$ & $\begin{array}{l}\text { Remote sites with high } \\
\text { fuel costs and/or low grid } \\
\text { reliability }\end{array}$ & $\begin{array}{l}\text { Sites with demand, time- } \\
\text { of-use charges, or ancillary } \\
\text { service markets }\end{array}$ & $\begin{array}{l}\text { Sites in deregulated } \\
\text { market with interested } \\
\text { off-taker }\end{array}$ \\
\hline $\begin{array}{l}\text { Primary power } \\
\text { supply }\end{array}$ & Utility grid & $\begin{array}{l}\text { DERs, typically including } \\
\text { generators }\end{array}$ & Utility grid + DERs & Utility grid \\
\hline $\begin{array}{l}\text { Backup power } \\
\text { supply }\end{array}$ & UPS & $\begin{array}{l}\text { Not impacted by grid } \\
\text { disruptions }\end{array}$ & DERs & DERs \\
\hline
\end{tabular}

\section{Technical Solutions}

\section{Use Cases for Distributed Battery Storage}

Battery storage has long been used as an uninterruptible power source (UPS) for critical loads like servers and medical equipment. In this application, the battery is typically kept at or close to $100 \%$ state of charge, and the battery is not used for additional revenue-generating purposes. During a grid outage,

\section{Storage Supports}

Resilience in the

\section{Dominican Republic}

During Hurricanes Irma and Maria in 2017, the Dominican Republic was able to utilize 20 MW of battery storage at two power plants to support grid stability, frequency control, and critical reliability services of the interconnected power system. Many island nations impacted by hurricanes are now planning to scale up deployment of microgrids, renewable energy, and storage systems to support resilience of the power system during future storm occurrences. a UPS maintains power continuity and typically provides power for up to a few hours, until a system that can provide power for a longer duration can be brought online.

Batteries can also be a critical part of off-grid systems that are not served by a utility grid. Batteries in off-grid systems typically help to balance variable generation sources (like solar or wind) by storing excess energy when generation exceeds the load and discharging energy when generation is less than the load.

Grid-connected batteries, often coupled with renewable technologies like solar photovoltaics (PV), have the potential to provide power in the event of a grid outage (if installed with appropriate islanding controls). While the grid is operational, the battery is dispatched to provide value such as utility bill savings, grid services (like capacity products and voltage support), and/or to store excess generation of other distributed energy resources (DERs). If the grid goes down, the batteries coupled with other DERs can provide power for extended periods of time. These combined systems can decrease the size of generation assets used solely for backup power, extend limited fuel supply, provide a second layer of backup (redundancy), and enable a fully renewable backup system (when coupled with renewable energy technologies) that does not need refueling.

Finally, sites could host a large-scale renewable energy and storage system where they are not the primary energy consumer. While the grid is operational, the host-site would not use the power generated. Instead, the off-taker (often a utility) would operate the system and take the generated power. However, in the event the grid goes down, with proper islanding controls in place, the host site could utilize those technologies to power critical loads.

The table above summarizes four use cases for customer-sited battery storage systems.

\section{Value Streams}

The most common value stream for distributed battery storage is lowering the cost of utility purchases by offsetting high demand charges or shifting electricity use from high- to low-cost periods (energy arbitrage). Battery storage can also generate revenue by participating in utility demand response programs. Depending on how the baseline for savings is calculated, it may be challenging to utilize the full potential 
of the battery through demand response participation. There are also emerging opportunities for distributed battery storage to participate in wholesale markets, where, in aggregate, they can provide frequency regulation and capacity. Read more: Battery 101 Series: Use Cases and Value Streams for Energy Storage.

\section{Utility-Scale Storage}

In the event of a grid outage, utilities can use battery storage to black-start the system. During normal operations, utility-scale battery storage can provide significant value, although its value is not always compensated in electricity markets. As with distributed storage, utility-scale storage can provide grid stability services, perform energy arbitrage, help meet system-wide peaks, and provide value through transmission and distribution replacement and deferral. Read more about utility-scale battery storage value streams: GridScale Battery Storage: Frequent Asked Questions.

\section{Technology Mix and Size for Resilience}

The following section outlines three considerations for selecting and sizing technologies for resilience: critical load, anticipated outage duration, and the value of resilience.

\section{Critical Load To Be Served}

An important consideration is the critical load, or the load that will be served by the backup power system in the event of a grid outage. The critical load is usually different from the typical load and could be either larger or smaller with different shape, magnitude, and timing of peak. This load will impact the technology size and selection of the backup power solution. The critical load may not always be known but can be estimated several different ways:
- A simple way to estimate the critical load is as a percentage of the typical load. Using this method, the critical load can be smaller or larger in magnitude than the typical load but would have the same shape and timing of peak load.

- Some sites may have a critical load panel. If there is a meter measuring this load, it is typically the most accurate estimate of a critical load.

- The critical load can be estimated by adding up the power requirements of the individual critical components, such as heating, ventilation, and airconditioning (HVAC) or plug loads. This may work well if the critical load only comprises a few components.

There may be different levels of critical loads, including some that are very critical and must be powered as soon as the grid goes down, and some that have a longer disruption tolerance but are still important.

\section{Outage Duration}

Another consideration that will impact a backup solution is the length of outage period. For short-duration outages (minutes to hours), battery storage has long been used to provide uninterruptible power for critical loads like data servers. Because they are expensive and typically not connected to generation sources, UPSes typically provide power for a maximum of a few hours.

Diesel generators are another common backup solution. The length of time a diesel generator can provide power depends on the amount of fuel supply available on-site or through re-supply. Typically, fuel stored can power a diesel generator up to a few days. Integrating renewable energy technologies and battery storage can help extend a limited fuel supply.
Utility Partnerships Provides Resilient Power in Hawaii

The U.S Navy base Pacific Missile Range Facility, located in Kauai, Hawaii, recently partnered with their servicing utility, Kauai Island Utility Cooperative, to host $19.3 \mathrm{MW}$ of solar PV and 70 MWh of battery energy storage. During normal conditions, the system will provide power to the utility grid, but in the event the grid goes down, Pacific Missile Range Facility can utilize the system to provide power to site critical loads. This project supports both the U.S. state of Hawaii's 100\% renewable goal and the U.S. Navy's requirements for mission assurance.

If a site is anticipating an outage lasting more than a few days, fuel stored on-site may not be sufficient. A site may want to consider other solutions, such as a natural gas generator, that does not require on-site fuel storage, or a solution comprising solar PV and battery storage, which could provide power to a site without the constraint of fuel availability.

\section{Valuing Resilience}

Estimating and incorporating the value of resilience in a decision-making process can significantly impact system economics. Resilience can be quantified through performance-based metrics such as customer outage time, load not served, or time to recover. It can be valued as the avoided cost of an outage (loss of revenue, cost of damage, or cost to recover). However, few mechanisms currently exist to monetize the resilience value that storage and 
other solutions can provide. Read more about quantifying, valuing, and monetizing resilience: Valuing Resilience In Electricity Systems.

\section{Resilient Energy Platform}

The USAID-NREL Partnership's Resilient Energy Platform helps countries and localities address power system vulnerabilities by providing strategic resources and direct country support to enable planning and deployment of resilient energy solutions. This includes expertly curated reference material, training materials, data, tools, and direct technical assistance in planning resilient, sustainable, and secure power systems. Ultimately, these resources enable decision makers to assess power sector vulnerabilities, identify resilience solutions, and make informed decisions to enhance energy sector resilience at all scales, including local, regional, and national scales. To learn more about the technical solutions highlighted in this fact sheet, visit the Resilient Energy Platform website at: www.resilientenergy.org.

\section{Additional Resources}

Bowen, Thomas, llya Chernyakhovskiy, and Paul Denholm. 2019. "Grid-Scale Battery Storage Frequently Asked Questions." Golden, CO: NREL. NREL/ TP-6A20-74426. https://www.nrel.gov/ docs/fy19osti/74426.pdf.
DOE (U.S. Department of Energy). 2018.

"Considerations for Implementing PV plus Storage Systems at Federal Buildings and Campuses."Washington, D.C.: DOE. DOE/GO-102018-5114. https://www.energy.gov/sites/prod/ files/2018/08/f55/pv_plus_storage.pdf.

Else, Jessica. 2017."PMRF and KIUC strike deal to house facility on westside."The Garden Island. https://www.thegardenisland.com/2017/12/22/hawaii-news/ pmrf-and-kiuc-strike-deal-to-housefacility-on-westside/.

Hotchkiss, Eliza, and Sadie Cox. 2019. "Power Sector Resilience Technical Solutions." Golden, CO: NREL. NREL/ TP-6A20-73506. https://resilientenergy.org/training-and-resources/ quick-reads/73506-rep_transformative_ stech-v9.pdf/view.

Lin, Daniel. 2017. “How a Pacific Island Changed From Diesel to 100\% Solar Power". National Geographic. https:// www.nationalgeographic.com/science/ article/tau-american-samoa-solar-power-microgrid-tesla-solarcity\#close.

McLaren, Joyce. 2016. "Use Cases and Value Streams for Energy Storage." Blog, NREL. March 25, 2016. https://www. nrel.gov/state-local-tribal/blog/posts/ batteries-101-series-use-cases-and-value-streams-for-energy-storage.html.
Marqusee, Jeffrey, and Donald Jenket. 2020. "Reliability of emergency and standby diesel generators: Impact on energy resiliency solutions." Applied Energy 268 (June): 114918. https://www. sciencedirect.com/science/article/pii/ S030626192030430X?via\%3Dihub.

Mongird, K, V Fotedar, V Viswanathan, V Koritarov, P Balducci, B Hadjerioua, and J Alam. 2019. Energy Storage Technology and Cost Characterization Report. Washington, D.C.: DOE. PNNL28866. https://www.energy.gov/sites/ prod/files/2019/07/f65/Storage\%20 Cost\%20and\%20Performance\%20 Characterization\%20Report_Final.pdf.

NREL (National Renewable Energy Laboratory). 2018. "Valuing the Resilience Provided by Solar and Battery Energy Storage Systems." Golden, CO: NREL. NREL/BR-6A20-70679. https:// www.nrel.gov/docs/fy180sti/70679.pdf.

NREL. 2019. "Valuing Resilience in Electrical Systems." Golden, CO: NREL. NREL/FS-7A40-74673. https://www.nrel. gov/docs/fy19osti/74673.pdf.

Zinaman, Owen, Thomas Bowen, and Alexandra Aznar. 2020. An Overview of Behind-the-Meter Solar-Plus-Storage Regulatory Design. Golden, CO: NREL. NREL/TP-7A40-75283. https://www.nrel. gov/docs/fy20osti/75283.pdf.

\section{www.resilient-energy.org | www.nrel.gov/usaid-partnership}

This work was authored, in part, by the National Renewable Energy Laboratory (NREL), operated by Alliance for Sustainable Energy, LLC, for the U.S. Department of Energy (DOE) under Contract No. DE-AC3608GO28308. Funding provided by the United States Agency for International Development The views expressed in this report do not necessarily represent the views of the DOE or the U.S. Government, or any agency thereof, including USAID. (USAID) under Contract No. IAG-17-2050.

The Resilient Energy Platform provides expertly curated resources, training, tools, and technical assistance to enhance power sector resilience. The Resilient Energy Platform is supported by the U.S. Agency for International Development.

The USAID-NREL Partnership addresses critical challenges to scaling up advanced energy systems through global tools and technical assistance, including the Renewable Energy Data Explorer, Greening the Grid, the International Jobs and Economic Development Impacts tool, and the Resilient Energy Platform. More information can be found at: www.nrel.gov/usaid-partnership.

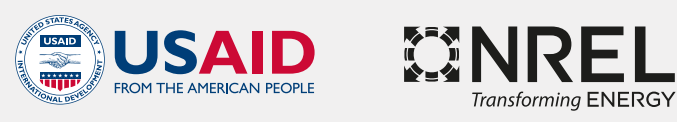

REexplorer
MAPPIN OUR ENERGY FutURE

